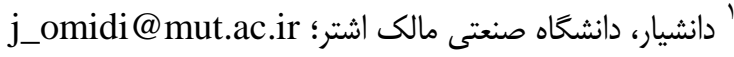

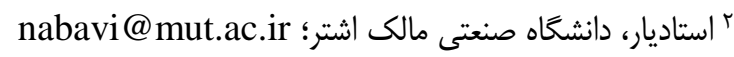

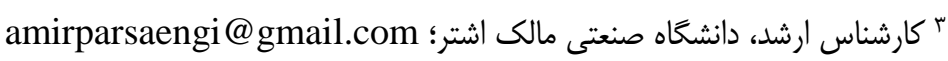

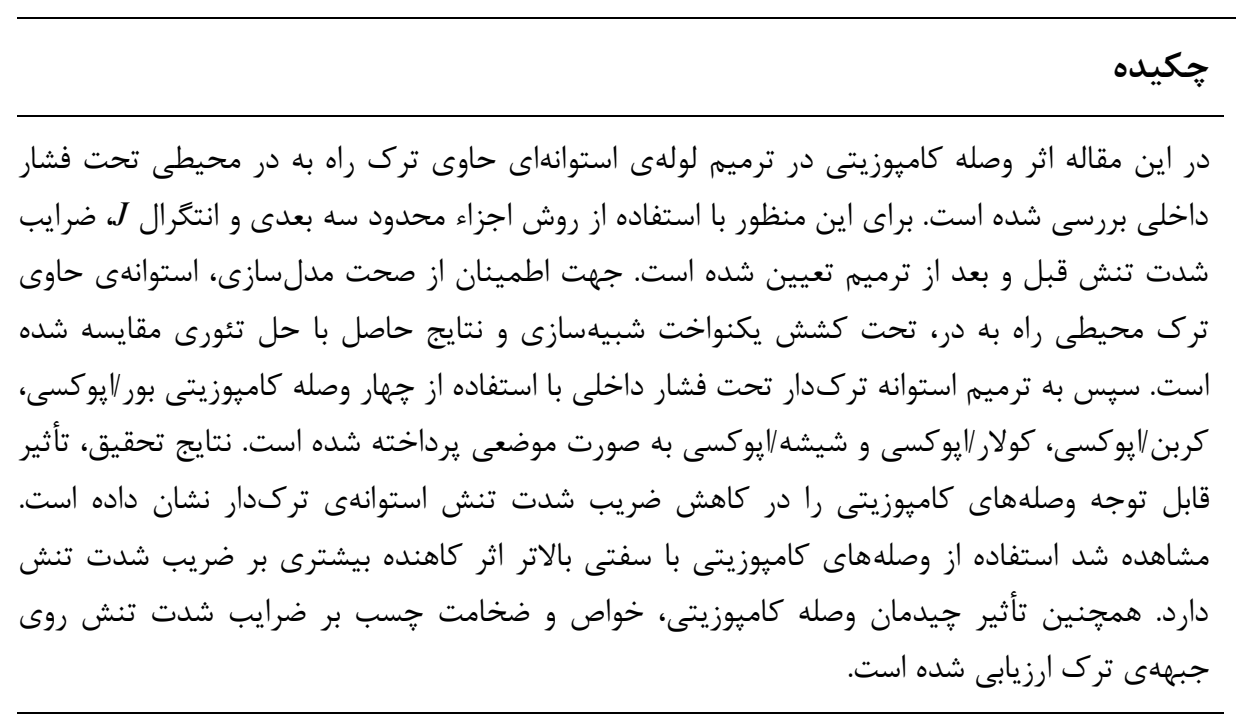

اطلاعات مقاله

\title{
The Repair of Circumferential Through-Wall Cracked Pipe by Using Local Composite Patch
}

\author{
Majid Jamal-Omidi ${ }^{1}$, Seyed Mehdi Nabavi ${ }^{2 *}$, Amir Hossien Parsania ${ }^{3}$ \\ ${ }^{1}$ Associate Professor, Malek Ashtar University of Technology; j_omidi@mut.ac.ir \\ ${ }^{2}$ Assistant Professor, Malek Ashtar University of Technology; nabavi@mut.ac.ir \\ ${ }^{3}$ Master of Science, Malek Ashtar University of Technology; amirparsaengi@gmail.com
}

\section{ARTICLE INFO}

Article History:

Received: 21 Sep. 2018

Accepted: 2 Nov. 2019

\section{Keywords:}

Cylindrical Pipe

Circumferential Through-Wall

Crack

Stress Intensity Factor

Local Composite Patch

Three-Dimensional Finite

Element Method

\begin{abstract}
In this paper, the effect of composite patch on cylindrical pipe with circumferential through-wall crack has been investigated under internal pressure. For this purpose, using three-dimensional finite element and $J$-integral, stress intensity factors is determined before and after the repair. In order to ensure the accuracy of modeling, a pipe with circumferential through-wall crack under uniform tension load is simulated and the results are compared with theoretical data. Then, the cracking cylinder is repaired using four composite patches of Boron/Epoxy, Carbon/Epoxy, Kevlar/Epoxy and Glass/Epoxy in a local manner. The results of study are shown the significant effect of composite patches on reducing the stress intensity factor of cracked cylinder. It is observed that the use of composite patches with higher stiffness has a more decreasing effect on stress intensity factor. Also, the effect of composite patch, properties and thickness of adhesive on stress intensity factors along crack front is evaluated.
\end{abstract}




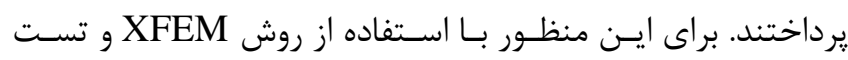

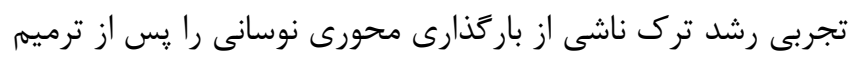

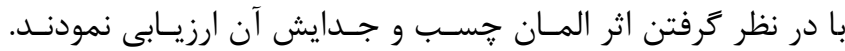

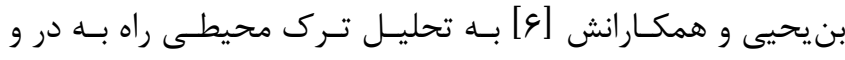

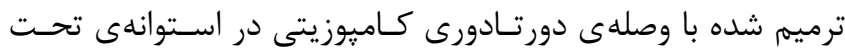

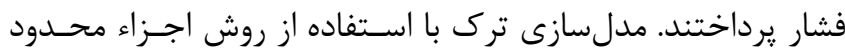

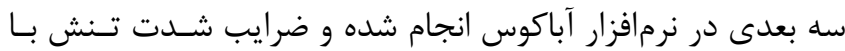

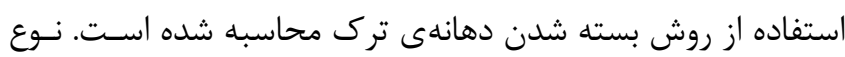

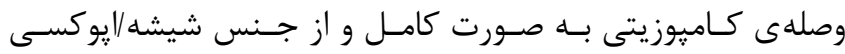

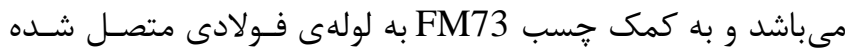

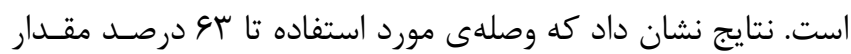
ضريب شدت تنش را كاهش مى دهد. آيتاللهى و همكارانش [V] به دله

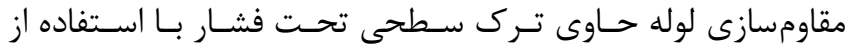
وصلهى دورتادورى كاميوزيتى از جنس كربن/ايوكسى يرداختند.

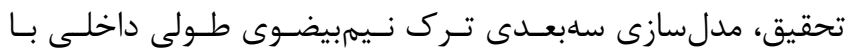

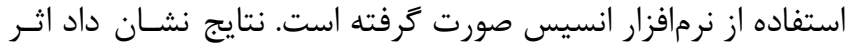
فشار داخلى روى مقدار ضريب شدت تنش در حالـت مقـاوم شــده

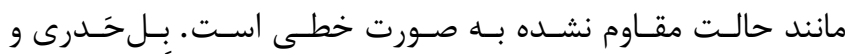

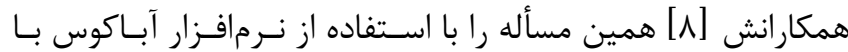

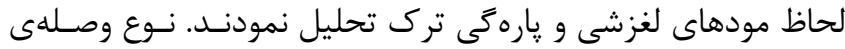

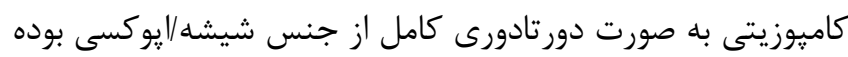

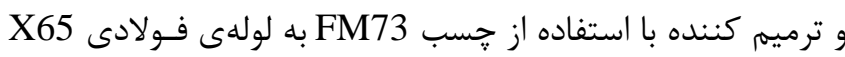

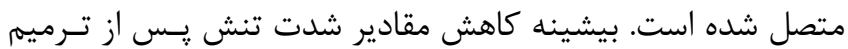

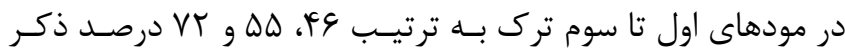

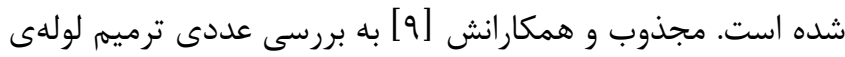

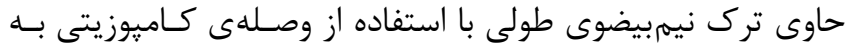

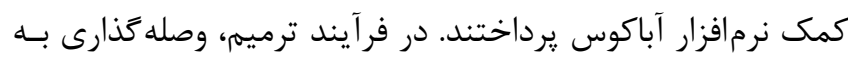

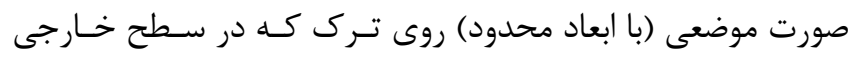

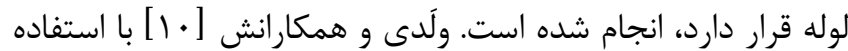

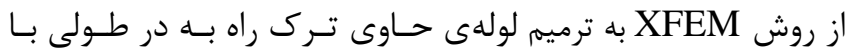

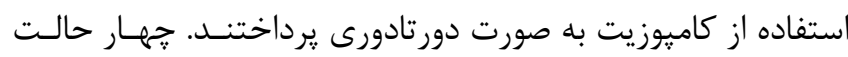

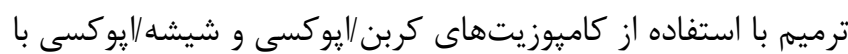

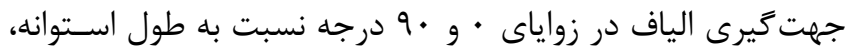

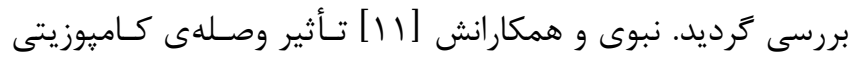
موضعى در ترميم لولهى تركدار تحت فشار داخلى را با اسـتفاده از

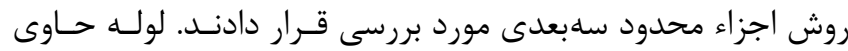

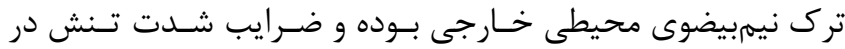

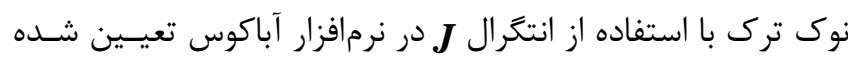

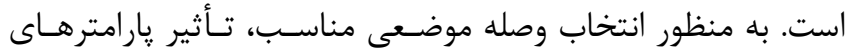
مختلف مانند طول، يهنا، ضخامت، جنس و زاويهى قراركيرى الياف קندلايهاى كاميوزيتى بر ضرايب شدت تــش ارزيـابى شــده اسـت.

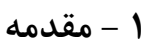
كشتىها و سازههاى دريايى در حين كار معمولاً دجـار آسـيبهـاى

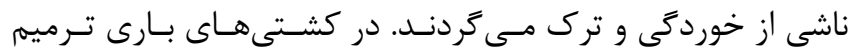

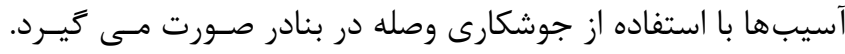

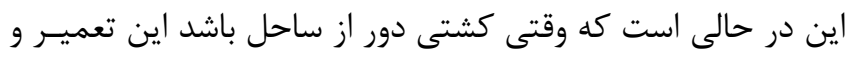

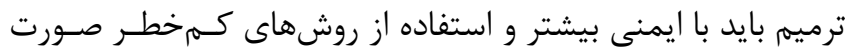

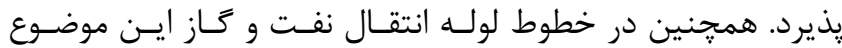

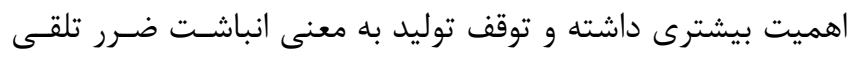

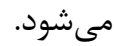
لوله ها، مخازن تحـت فشـار و سـيلندرهاى هيـدروليك از جملـهى

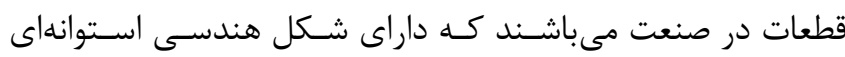

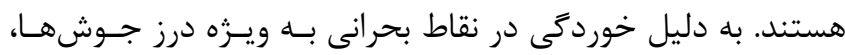

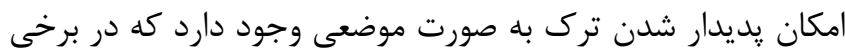
از موارد منجر به توقف توليد و هزينـههـاى تحميلـى مسى تحردد. از

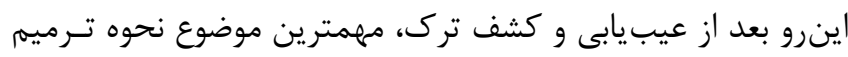

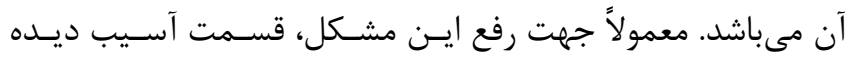

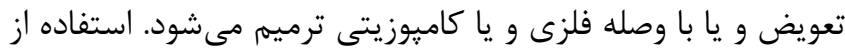

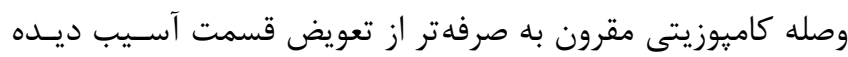
مىباشد و در اين روش نياز به توقف فر آيند انتقـال سـيال و خـارج شدن از وضعيت عملياتى وجود ندارد.

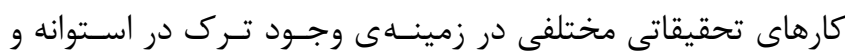

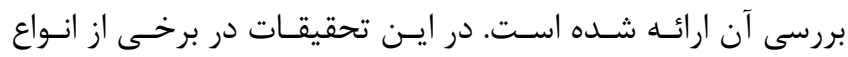
ترك هاى در نظر ترفته شده به صورت راه به در ' و در برخى ديخــر

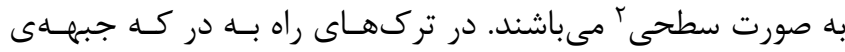

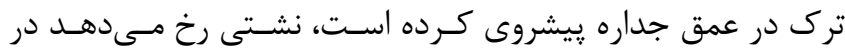

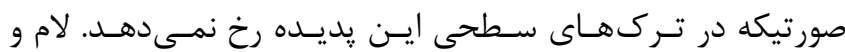

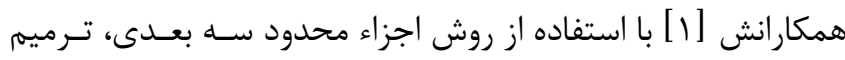

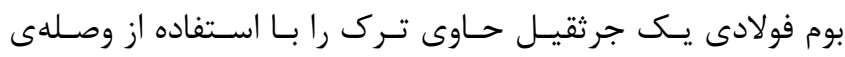

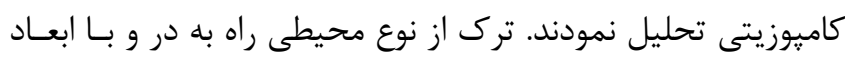
خاص و وصله به صورت يك طرفه در نظر كرفتـه شـده اسـت. اثـر

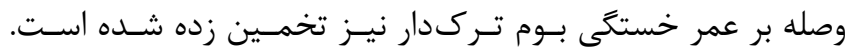

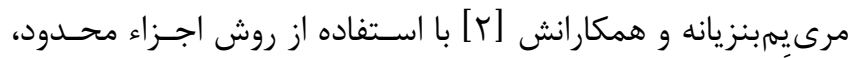

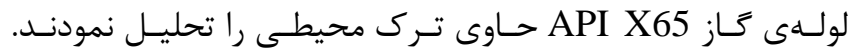
ارزيابى استفاده از وصلهى كاميوزيتى موضعى يكى طرفه و دو طرفئه

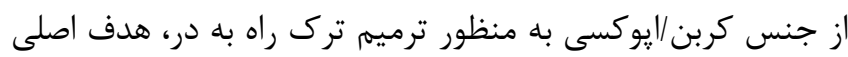

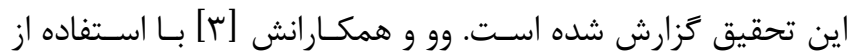

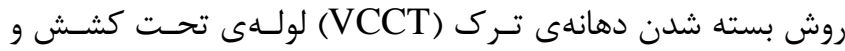

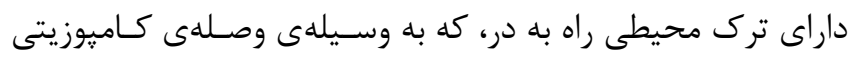

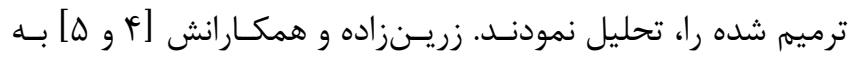
بررسى خستخى لولهى آلومينيومى حاوى ترك راه بـــه در محيطى

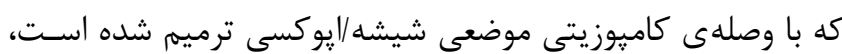


حاوى ترك از حسب FM73 استفاده شده و ترميم در سطح بيرونى

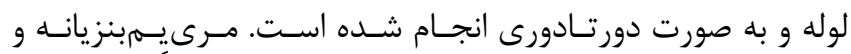

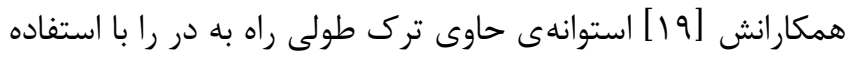

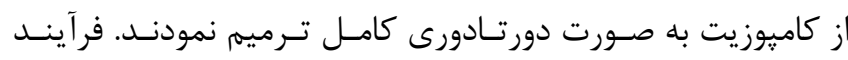

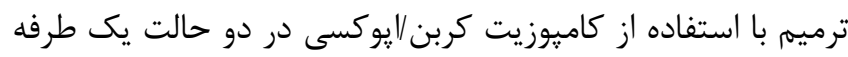

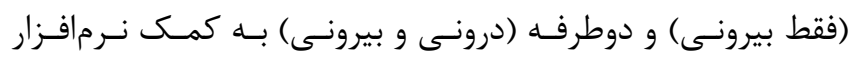
آباكوس صورت كرفته است.

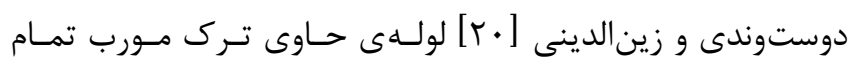

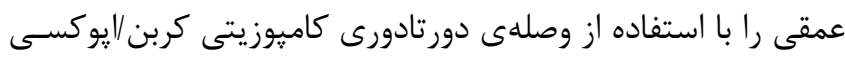

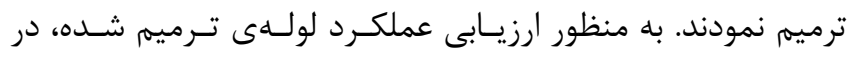

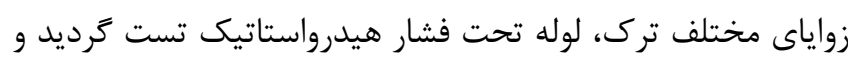

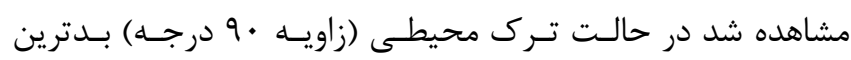

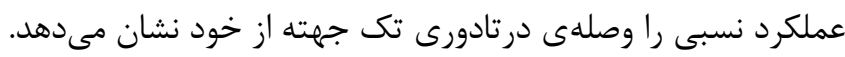

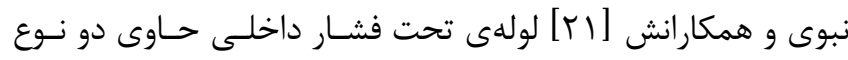

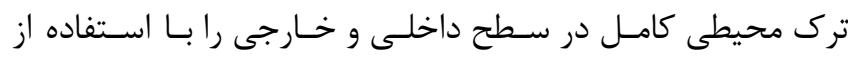

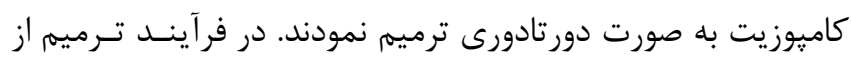

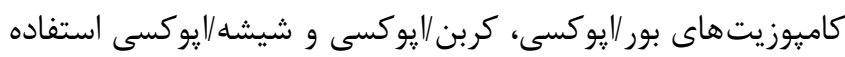

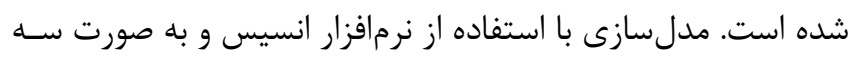

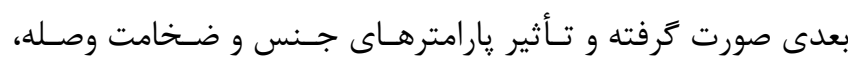

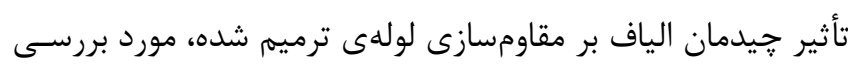
قرار كرفته است. همانكَونه كه ملاحظه مى شود، عمدهى تحلى تحليل هاى صورت كرفته در

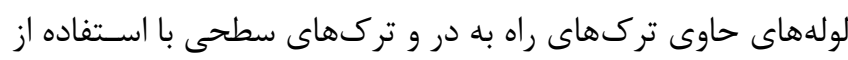

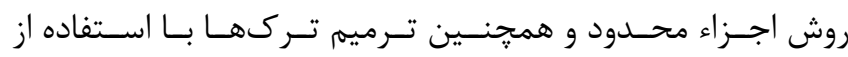

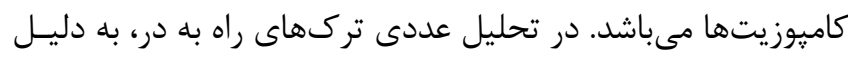

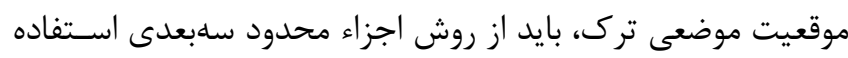

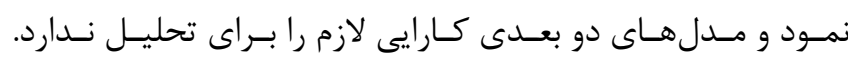

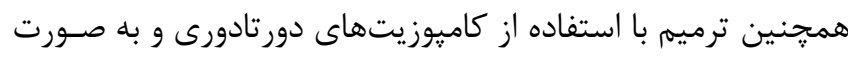

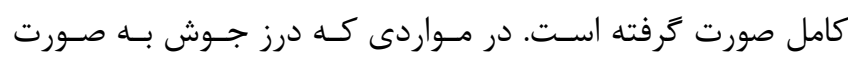

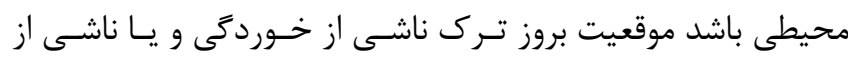

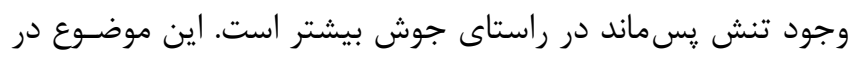

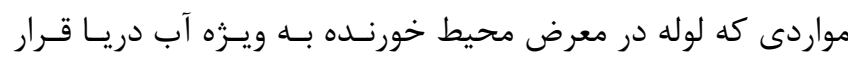

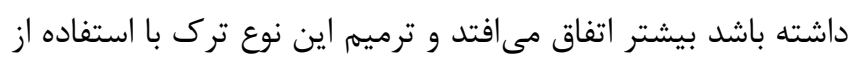
وصلهى موضعى تاكنون صورت نكرفته است.

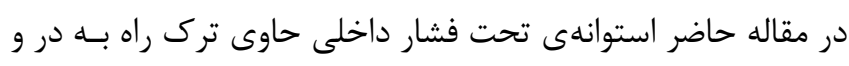

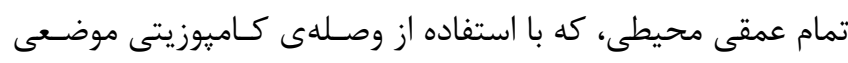

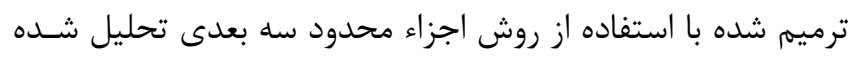

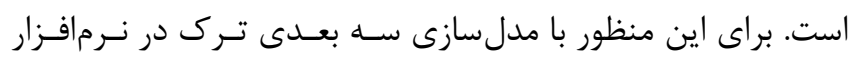

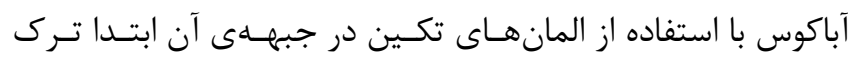

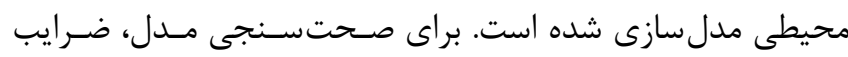

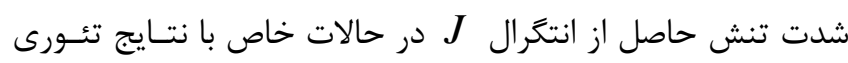

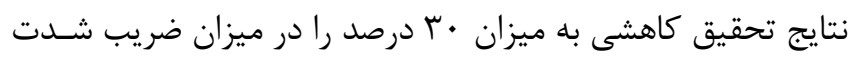

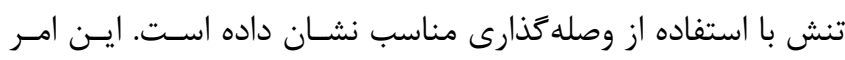

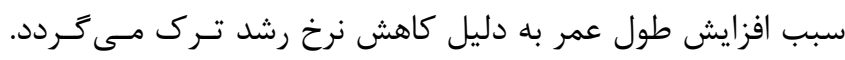

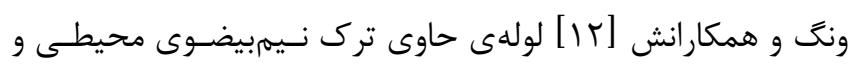

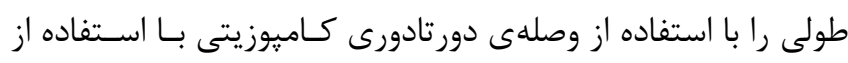

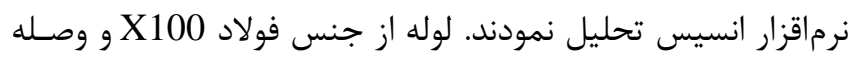

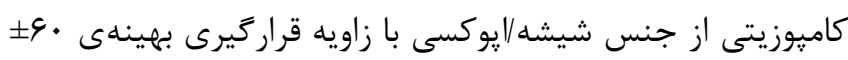
درجه مىباشد.

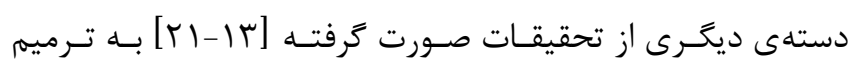

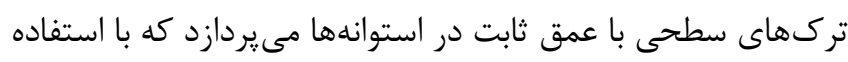

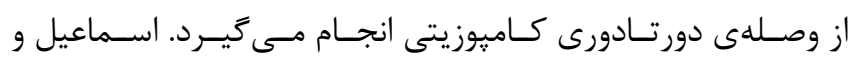

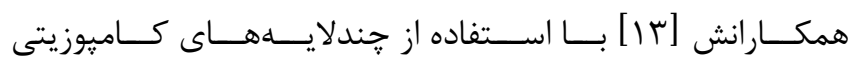

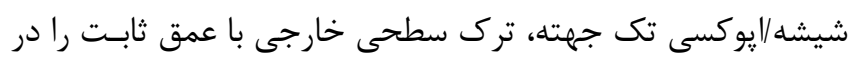

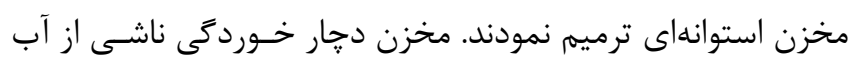

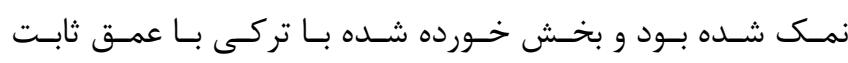

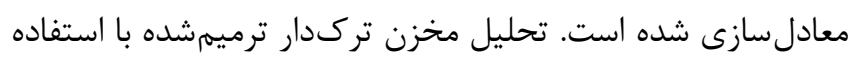

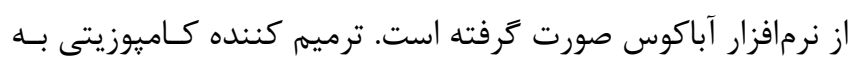

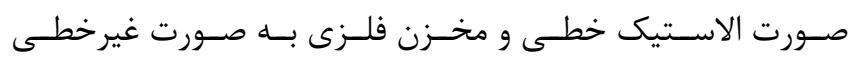

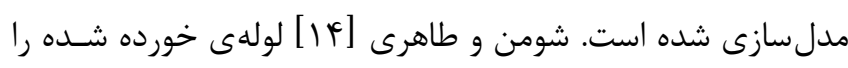

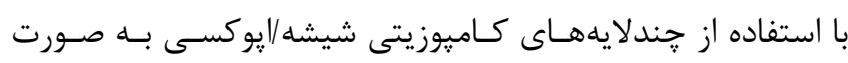

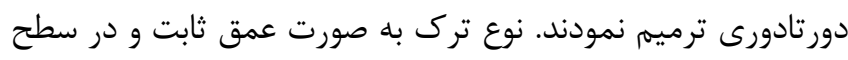

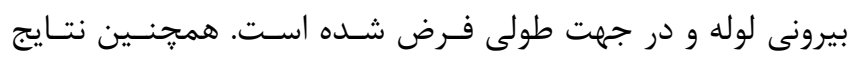

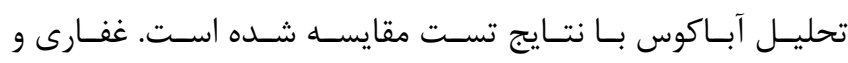

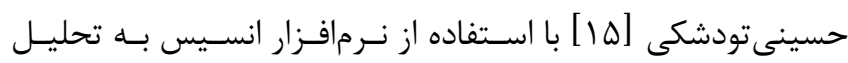

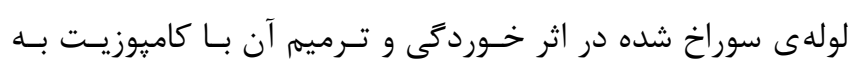

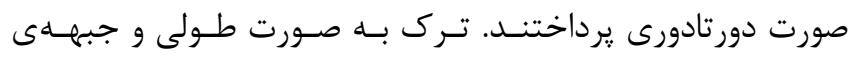

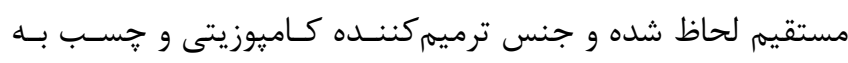

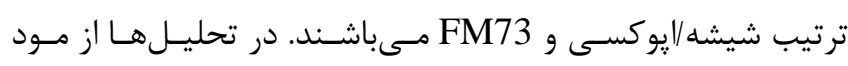

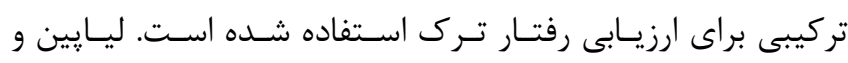

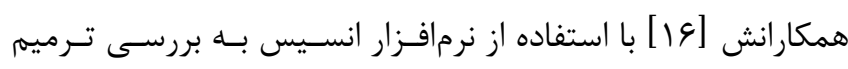

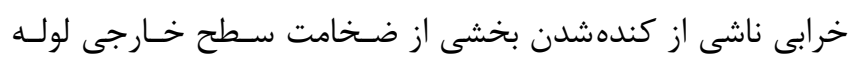

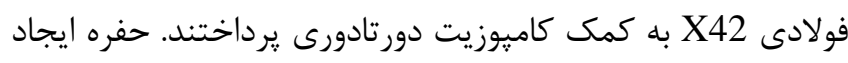

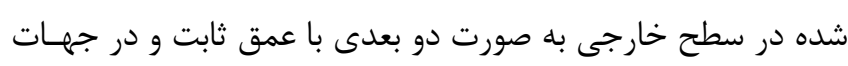

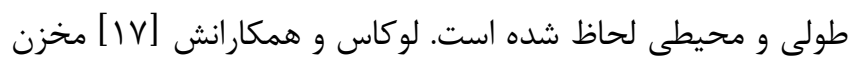

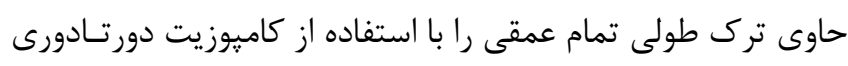

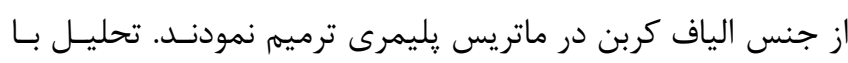

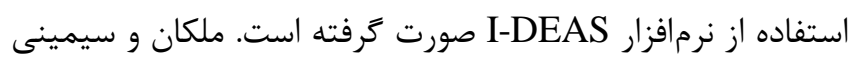

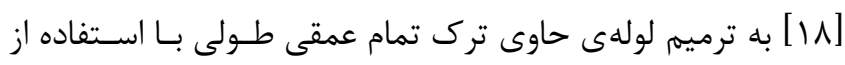

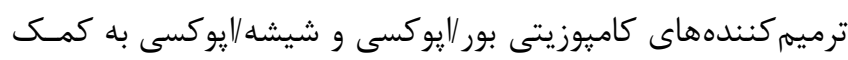

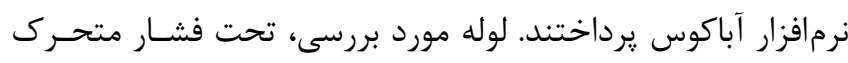

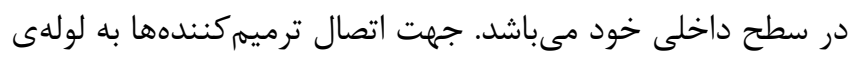


روش ديخر استفاده از انتخرال J مئباشد كه اين معايب را نداشـتهـ

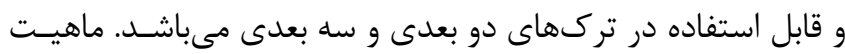

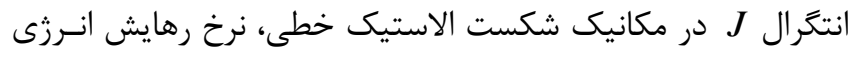

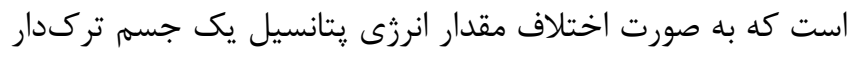
در دو طول ترك مختلف در قالب يك انتكَرال به صورت زير تعريف

مىشود:

$$
J=\oint_{\Gamma}\left[W n_{1}-t_{i}\left(\partial u_{i} / \partial x_{1}\right)\right] d s
$$

كه در آن م مسير بسته دلخواه است كه الزاماً بايد از سطح يـايين

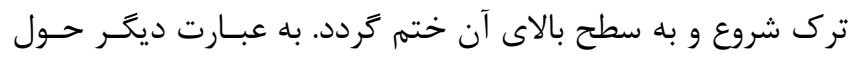

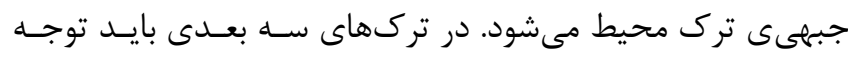

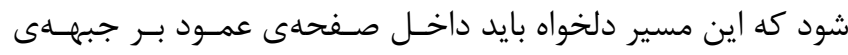

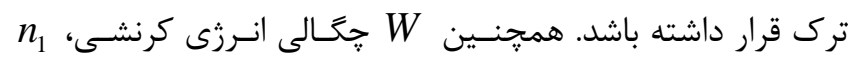

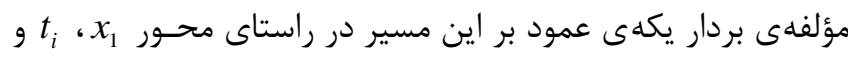

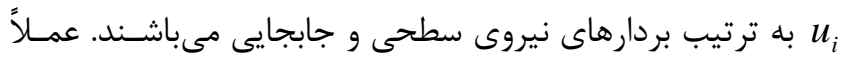

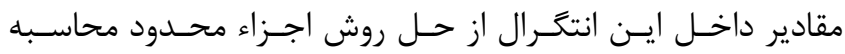

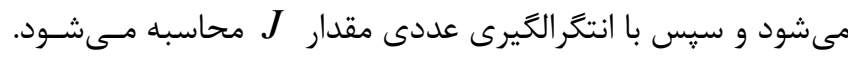

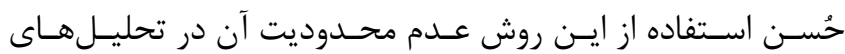

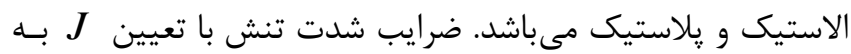

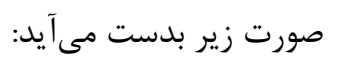

$$
K_{I}=\sqrt{\frac{8 \mu J}{(1+k)}}
$$

\section{r - مدل هندسى و مواد}

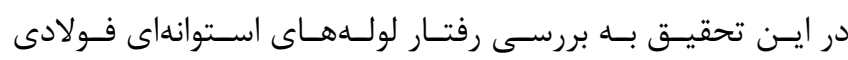

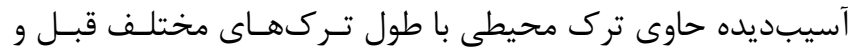

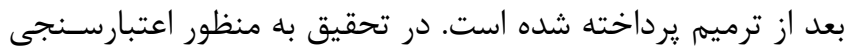

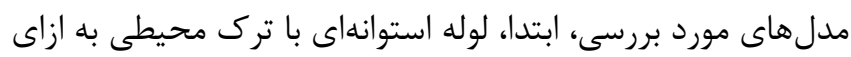

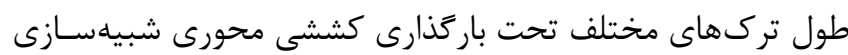
و تجزيه و تحليل شده است. در اين حالت لوله تركدار بــه صـورت

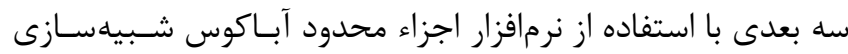

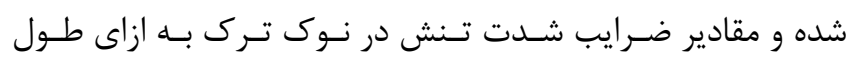
ترك هاى مختلف محاسبه و با نتايج تئورى مقايسه و ارزيـابى شـده است. سيس به ترميم لوله استوانهاى حاوى ترك محيطى با استفاده

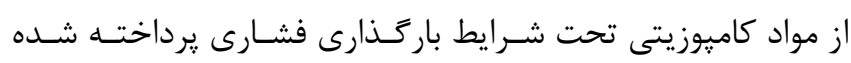

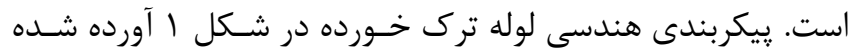
است. لوله استوانهاى داراى شعاع داخلـى ف آن

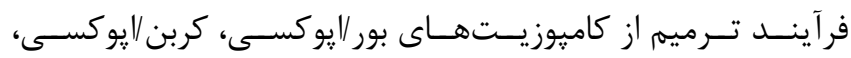

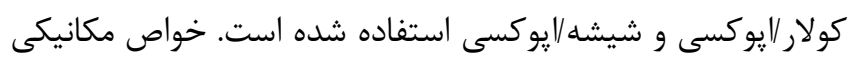

مقايسه شده است. يس از اطمينــان از دقـت و صـحت مـدل تسـازى ترك، به ترميهم استوانهى حاوى ترك با استفاده از وصلهى موضسعى لهى

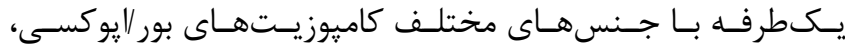
كربن/ايوكسى، كولار//يوكسى و شيشه/ايوكسى يرداخته شده اسـت. همجنين در فرآيند تحقيق تاثير جيدمان وصله كاميوزيتى، خـواص جسب و ضخامت جسب بر روى ضرايب شدت تـنش روى جبهـهـى

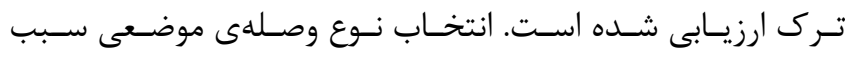
صرفهجويى در مصرف مواد كاميوزيتى مى گردد.

\section{r - روش هاى تعيين ضرايب شدت تنش}

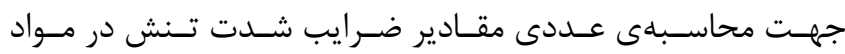

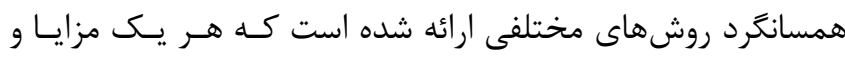

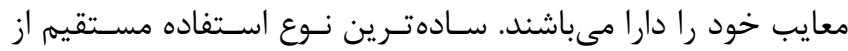
ميدان جابجايى حاصل از حل به روش اجزاء محدود در حول نـوك مانى

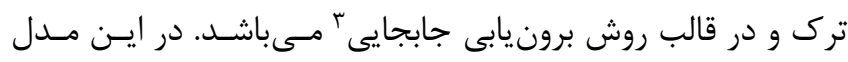

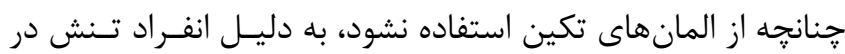

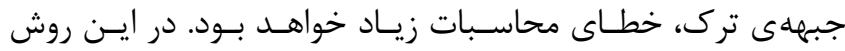
ضرايب شدت تنش به صورت زير تعيين مىشود: $K_{I}=\frac{2 \mu}{(1+k)} \sqrt{\frac{2 \pi}{\delta}} U_{y}$

كـه در آن تــنش صـفحهاى و (3-4v) مسىباشـد. همجنــين $\delta$ فاصـله عمـودى از جبهـهـى تـرك و $U_{y}$ جابجايى نقاط در راستاى عمودى و حاصـل از روش اجـزاء محــدود است.

روش مشتق سفتى ^ بر مبناى انرزى استوار است. اساس اين نوع بـر

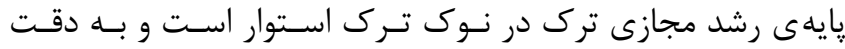

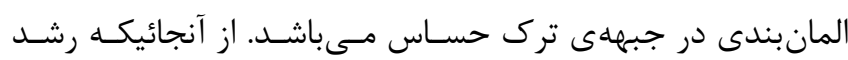

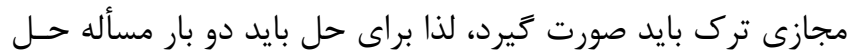

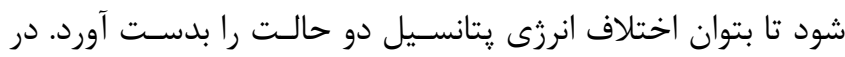

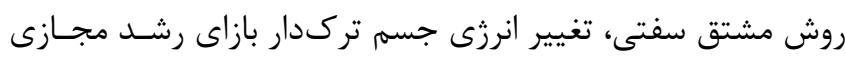
ترك مبناى تعيين ضرايب شدت تنش به صورت زير ميى مباشد:

$$
K_{I}^{2}=-\frac{H}{2}\{u\}^{T}(\partial[K] / \partial l)\{u\}
$$

كه در آن [l] طول ترك مسى باشـد. همجنـين E=E صفحهاى و ( $H=E /\left(1-v^{2}\right.$ در حالـت كـرنش صـفحهاى اسـت. مشتق سفتى در اين معادله به ازاى رشد مجازى تركى بـه انـدازهى بسيار كوجى نسبت به طول المان صورت مى گيرد. 
توزيع تنش اطراف نوى ترك به ترتيب در شكلهـاى ؟ و ب آورده شده است.

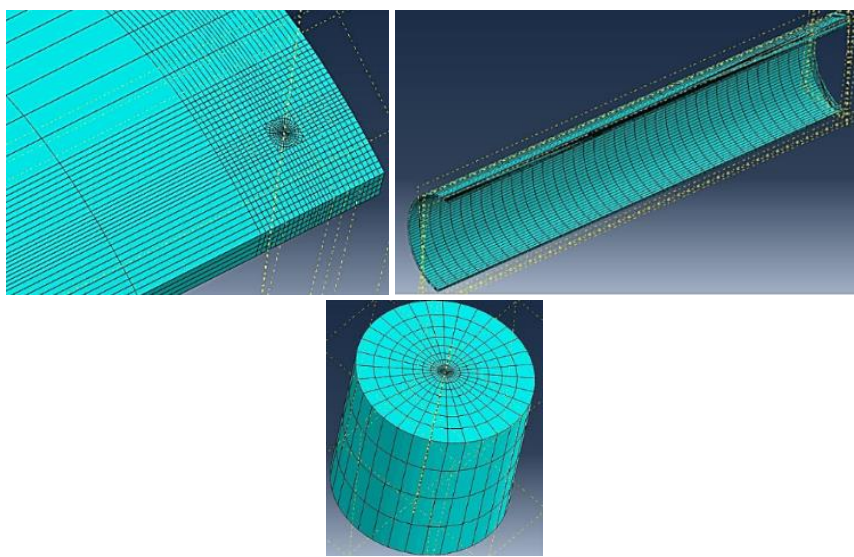

شكل r - نمايش مش بندى لوله تركدار با ترى محيطى

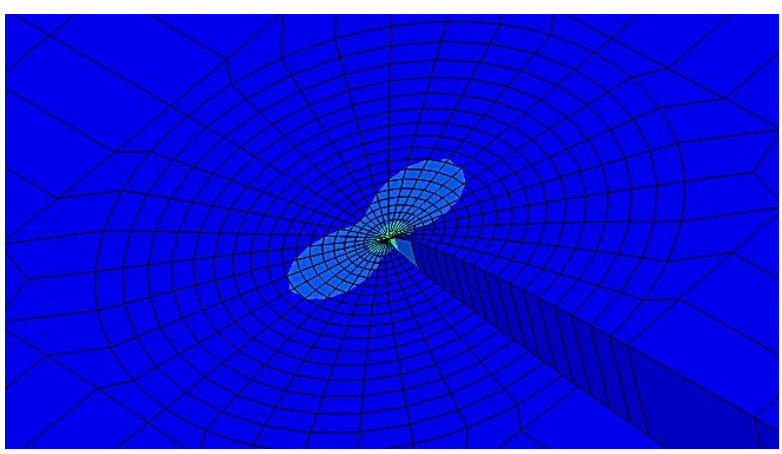

شكل r - نمايش توزيع تنش در اطراف نوك ترك

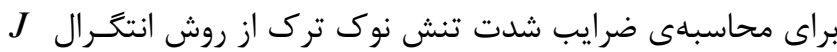

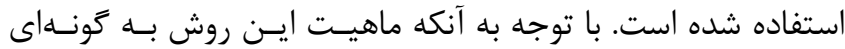

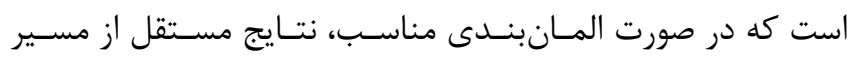
انتخابى براى تعيين ضريب شدت تنش مسىباشــند، لـذا نتـايج هـر

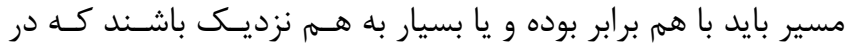
اين صورت نتايج همكرا خوانده مىشوند. از ايسنرو همكر ايسى نتـايج انتخرال J لبا تغيير و انتخاب المانبندى مناسب در كليهى مدلهــا اعمال شده است. نتايج ضريب شدت تنش به ازاى طول تـركهـاى مختلف براى ينج مسير در جدول كآورده شده است. جدول Y - نتايج ضريب شدت تنش به ازاى طول تركهاى مختلف در

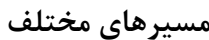

\begin{tabular}{|c|c|c|c|c|c|}
\hline \multicolumn{5}{|c|}{$K I\left[M P a . m^{1 / 2}\right]$} & \multirow{2}{*}{$\begin{array}{c}\text { طول ترك، } a \mathrm{~mm}] \\
\text { [mm }\end{array}$} \\
\hline مسير هـ & مسير F & مسير r & مسير r & مسير 1 & \\
\hline rq/q $4 q$ & $r q / q F V$ & $r q / q F V$ & rq/q४q & $r q / 4 \Delta V$ & $r Q / \mathcal{F}$ \\
\hline rN/qTV & rN/qTQ & TN/qTQ & rN/qTF & rA/VTA & rN/l \\
\hline FV/VEA & FV/VGG & FV/VGG & FV/VED & $F V / r \varepsilon D$ & $\Delta \cdot / \Lambda$ \\
\hline$\Delta \varepsilon / T \vee \Delta$ & $\Delta \& / T V R$ & $\Delta G / T V T$ & $\Delta G / T V T$ & $\Delta \varepsilon / \cdot 1 T$ & \&M/D \\
\hline 9919.9 & $4 \cdot V / 94$ & $99 / 9 \cdot V$ & 9919.9 & $98 / I T F$ & $V \& / T$ \\
\hline$V V / \Delta \cdot q$ & $V V / \Delta \cdot V$ & $V V / \Delta \cdot V$ & $V V / 0 \cdot G$ & $V V / \cdot r q$ & $19 / 9$ \\
\hline
\end{tabular}

لوله تركدار، وصلههاى كاميوزيتى و جسب در جدول آآورده شده

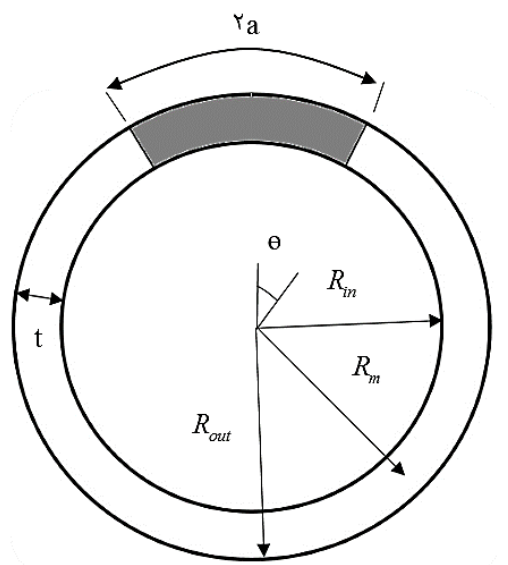

شكل ا - لوله تركدار حاوى ترك محيطى راه به در تمام عمقى

جدول 1 - خواص مكانيكى مواد بررسى در تحقيق حاضر [rr]

\begin{tabular}{|c|c|c|c|c|c|c|}
\hline | شيشه | & ايوكولار| & ايوكربن & ايوكسى | بور & קسب & فولاد & خواص \\
\hline$f_{1}$ & $\Lambda$. & $I V T / F$ & $r \cdot \Lambda$ & $r / \Delta \Delta$ & $r \cdot$. & $\begin{array}{c}E_{1} \\
{[G P a]}\end{array}$ \\
\hline IT & $\Delta / \Delta$. & $1 \cdot / T_{F}$ & $r \Delta / T^{*}$. & - & - & $\begin{array}{l}E_{2}=E_{3} \\
{[G P a]}\end{array}$ \\
\hline$\Delta / \Delta$. & $T / T$. & F/AT & $V / T F$ & - & - & $\begin{array}{c}G_{13}=G_{12} \\
{[G P a]}\end{array}$ \\
\hline$r / \Delta$. & $1 / \lambda$. & $r / l$. & $f / q F$ & - & - & $\begin{array}{c}G_{23} \\
{[G P a]}\end{array}$ \\
\hline$\cdot / r \Lambda$ & $\cdot / \mu r$ & $\cdot \pi$. & $\cdot / / V$ & . & rr/. & $v_{13}=v_{12}$ \\
\hline$\cdot 10$. & $\cdot / k$. & $\cdot / 11$ & $.1 \cdot 4$ & - & - & $v_{23}$ \\
\hline
\end{tabular}

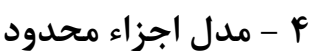

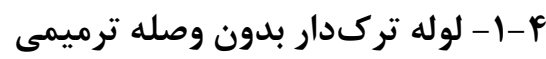

در اين بخش جهت اعتبار بخشى مدل هاى يِيشــهـادى، ابتـدا لولـه

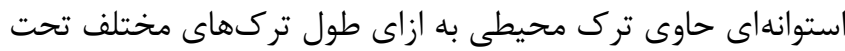

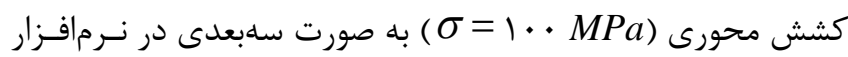

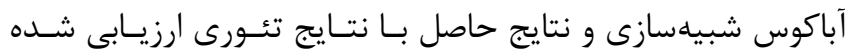

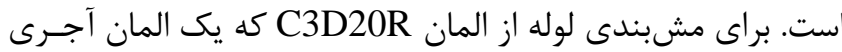

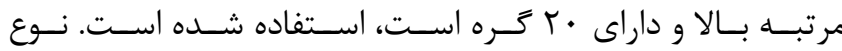

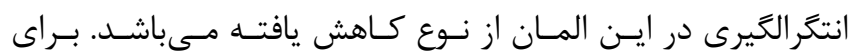

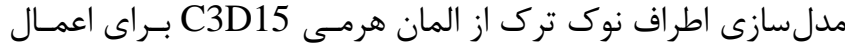

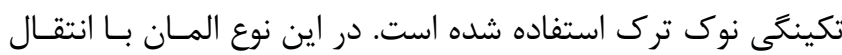

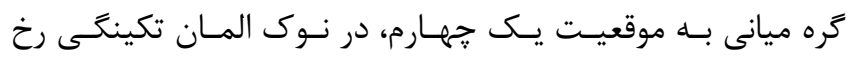

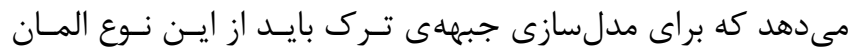

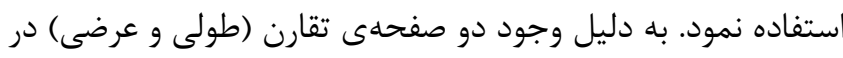

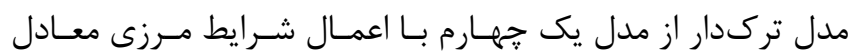

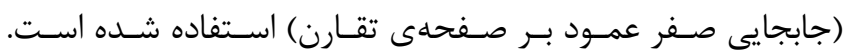
مشبندى نمونه و يالايش مش در ناحيه نوك ترك و نتـايج عـددى 
بيرونى تحت بار گذارى كششى در جدول f و شـكل f نمـايش داده شده است.

جدول F - ضريب شدت تنش روى جبهه ترى براى طول ترك مختلف در

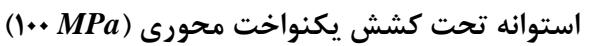

\begin{tabular}{|c|c|c|c|c|c|c|}
\hline \multicolumn{6}{|c|}{$K I\left[M P a . m^{1 / 2}\right]$} & \multirow{3}{*}{ شماره گره } \\
\hline NN/9 & $V G / T$ & Gr/D & $\Delta \cdot / \Lambda$ & rN/I & $r \Delta / \mathcal{F}$ & \\
\hline$[\mathrm{mm}]$ & {$[\mathrm{mm}]$} & {$[\mathrm{mm}]$} & {$[\mathrm{mm}]$} & {$[\mathrm{mm}]$} & {$[\mathrm{mm}]$} & \\
\hline$V V / \Delta \cdot$ & 9419. & $\Delta \varphi / T V$ & $F V / V$. & rN/qT & $r q / q r$ & I (External) \\
\hline$\Lambda F / \Lambda \Delta$ & $\mathrm{VH} / \cdot \mathrm{G}$ & GY/AT & $\Delta r / T q$ & FT/DG & . & $r$ \\
\hline$\lambda \uparrow|q|$ & $V F / l$. & $9 \pi / 90$ & $\Delta F / \cdots$ & Fr/Aq & q & r \\
\hline$\Lambda F / T \Lambda$ & $V Y / q$. & $G T / F V$ & س & $F T / F$. & $M T / G F$ & f \\
\hline$\wedge \uparrow / 9 \varphi$ & $V Y / \cdot \Delta$ & $91 / 99$ & $01 / 99$ & $f \mid / V$. & $r r / \cdot$. & $\Delta$ \\
\hline$\Lambda r / 99$ & $\vee 1 / 9 \Delta$ & $4 \cdot 149$ & $\Delta \cdot / \cdot$ & $F \cdot / T V$ & I & 9 \\
\hline$\Lambda T / \cdot 9$ & VI/AF & $09 / 99$ & $\mathrm{Fq/r}$. & $\mathrm{r} / \Delta \Lambda$ & $r \cdot 19$. & $\checkmark$ \\
\hline NI/IT & $9 \wedge / 9 H$ & $\Delta \varphi / 9 \Delta$ & $4 \& / r q$ & rV/IF & rᄉ/Aq & $\Lambda$ \\
\hline$V V / \backslash Q$ & Gr/VA & $\Delta F / V G$ & $F / / 90$ & $r r / \cdot V$ & r\&/AG & $৭$ (Internal) \\
\hline
\end{tabular}

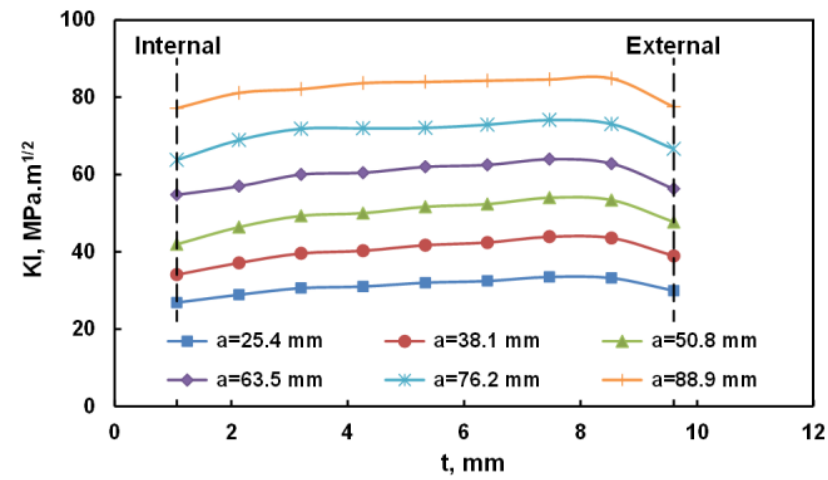

شكل F - نمايش ضرايب شدت تنش روى جبهه ترك براى طول تركهاى مختلف تحت كشش مشر

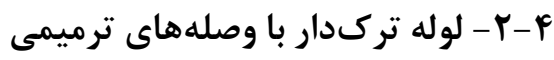

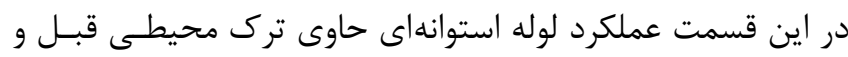

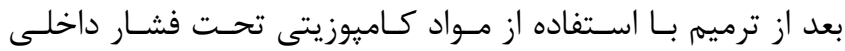
( $\sigma=\Delta M P a)$ درونى، فشار درونى و فشار عبارت است: $\sigma=\frac{P R_{i}}{2 t}$

نتايج ضـرايب شـدت تــش نقـاط مختلـف جبهـهـ تـرك در طـول

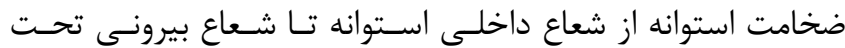
باركذارى فشارى در جدول ه و شكل ه نمايش داده شده است.
به منظور اثبات صحت مدل سازى عـددى از حـل تئـورى اســفاده

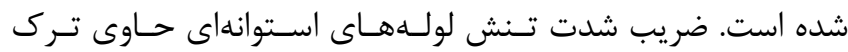
محيطى تحـت بارگحـذارى كششـى بـهـ صـورت زيــر قابـل محاسـبه مىباشد.

$K_{I}=\left(F_{t} \sigma_{t}\right) \sqrt{\pi R \theta}$

كه در آن Ft صورت رابطه (9) محاسبه مىشود.

$\sigma_{t}=\frac{P}{2 \pi R t}$

ضريب تصحيح كششى براى ضرايب شدت تنش در اسـتوانه حـاوى ترك محيطى تحت كشش محورى بر طبق مطالعات تاكاشـى [rr] به صورت رابطه (V) مىباشد.

$$
\begin{aligned}
F_{t}=\left[A_{t}\right. & +B_{t}(\theta / \pi)+C_{t}(\theta / \pi)^{2} \\
& \left.+D_{t}(\theta / \pi)^{3}+E_{t}(\theta / \pi)^{4}\right]
\end{aligned}
$$

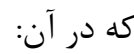

$A_{t}=1$;

$B_{t}=-1.040-3.183 \lambda-4.83 \lambda^{2}-2.369 \lambda^{3}$;

$C_{t}=16.71+23.10 \lambda+50.82 \lambda^{2}+18.02 \lambda^{3}$;

$D_{t}=-25.85-12.05 \lambda-87.24 \lambda^{2}-30.39 \lambda^{3}$;

$E_{t}=24.70-54.18 \lambda+18.09 \lambda 2+6.745 \lambda^{3}$;

$\lambda=\log \left(\frac{t}{R}\right)$

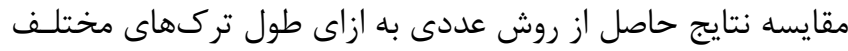

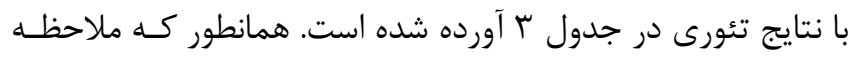
مى شود نتايج حل عددى تطـابق خـوبى را بـا نتـايج تئـورى نشـان

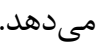

جدول r- مقايسه ضرايب شدت تنش در استوانه فولادى تركدار تحت

\begin{tabular}{|c|c|c|c|}
\hline $\begin{array}{l}\text { خ } \\
\%\end{array}$ & 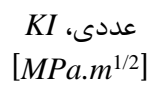 & $\begin{array}{c}\text { KI تئورى، } \\
{\left[M P a . m^{1 / 2}\right]}\end{array}$ & طول ترك، $\begin{array}{c}a \\
{[\mathrm{~mm}]}\end{array}$ \\
\hline G & $r q / q 4$ & rq/Ar & $r \Delta / \kappa$ \\
\hline - IDS & rN/qT & $|\wedge| \xi \mid$ & rN/I \\
\hline$\cdot / 4$. & FV/VG & $F V / \Delta V$ & $\Delta \cdot / \Lambda$ \\
\hline$\cdot / V \Lambda$ & $\Delta S / T V$ & $\Delta \Delta / \wedge \mu$ & $q \pi / \Delta$ \\
\hline $1 / 4 \pi$ & 9919. & $\Leftrightarrow \Delta / \varphi q$ & $V G / T$ \\
\hline $1 / 49$ & $V V / \Delta$. & $V G / T_{G}$ & $\Lambda N / q$ \\
\hline
\end{tabular}

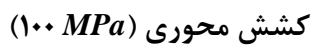

نتايج ضــرايب شـدت تــش نقـاط مختلـف جبهـــه تـرك در طـول

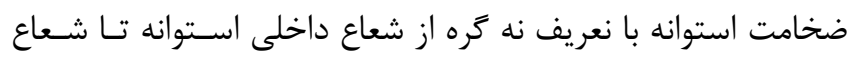




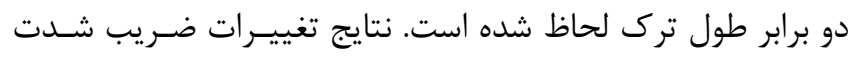

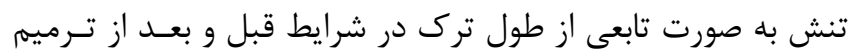

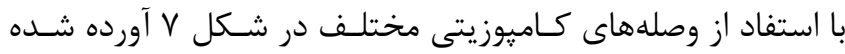

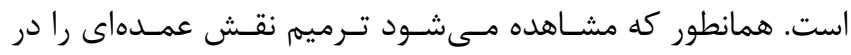
بازآورى استحكام قطعه تركدار ايفا مى كند. نتايج تحقيـق كاهشى

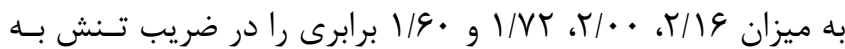
ترتيب براى وصله هاى بور/ايوكسى، كربن/ايوكسى، كولار/ايوكسى و شيشه/ايوكسى نشان داده است (جدول 9).
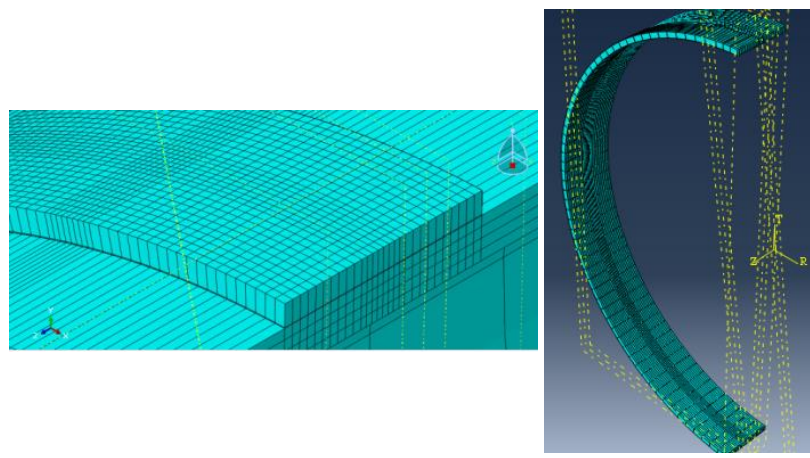

شكل 9 - نمايش مش بندى اجزا لوله تركدار ترميم شده

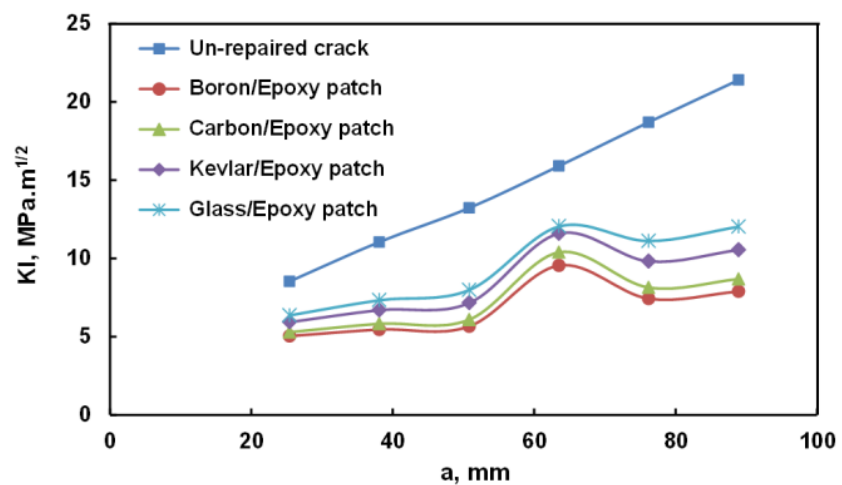

شكل V - تغييرات ضرايب شدت تنش در توى ترك (External) براى

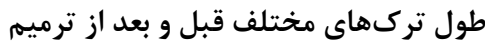

جدول \&- مقايسه ميانگين ضرايب شدت تنش قبل و بعد از ترميم به كمك وصله هاى كاميوزيتى

\begin{tabular}{|c|c|}
\hline ميانكَين ضريب شدت تنش در نوك ترك، & وضعيت استوانه تركدار \\
\hline $1 F / \Lambda$. & بدون ترميم \\
\hline GIAF & ترميم با وصله بور/ايوكسى \\
\hline$V / 4$. & ترميم با وصله كربن/ايوكسى \\
\hline N/GT & ترميم با وصله كولار/ايوكسى \\
\hline$q / \notin V$ & ترميم با وصله شيشه/يوكسى \\
\hline
\end{tabular}

جدول هـ ضريب شدت تنش روى جبهه ترى براى طول ترك مختلف در استوانه تحت فشار داخلى (DMa)

\begin{tabular}{|c|c|c|c|c|c|c|}
\hline \multicolumn{6}{|c|}{$K I\left[\mathrm{MPa} \mathrm{m}^{1 / 2}\right]$} & \multirow{2}{*}{ شماره گره } \\
\hline $\begin{array}{l}\text { 1N/q } \\
{[\mathrm{mm}]}\end{array}$ & $\begin{array}{l}\mathrm{V} / \mathrm{T} \\
{[\mathrm{mm}]}\end{array}$ & $\begin{array}{l}\text { s } / \Delta \\
{[\mathrm{mm}]}\end{array}$ & $\begin{array}{l}\Delta \cdot / \wedge \\
{[\mathrm{mm}]}\end{array}$ & $\begin{array}{l}\text { rN/l } \\
{[\mathrm{mm}]}\end{array}$ & $\begin{array}{l}r \Delta / \mathcal{F} \\
{[\mathrm{mm}]}\end{array}$ & \\
\hline$r) / r q$ & $1 N / V$. & $10 / 9$. & IT/Tr & $11 / \cdot 0$ & N/DT & I (External) \\
\hline$r r / \cdot \Delta$ & $19 / 9 r$ & $\mid V / \Delta \Lambda$ & $10 / \cdot 9$ & IT/KG & $9 / 49$ & r \\
\hline Tr/IT & $r \cdot / 4 q$ & IV/A9 & $I Q / T F$ & $\mid r / 49$ & $9 / \Delta F$ & r \\
\hline rT/QG & $r \cdot|r|$ & $I V / F V$ & $I F / V V$ & $\mid r / \cdot r$ & $9 / T^{F}$ & r \\
\hline TT/AV & $r \cdot 119$ & $I V / r \Delta$ & $\mid F / \Delta \Lambda$ & $11 / \lambda F$ & $9 / 1 r$ & $\Delta$ \\
\hline$r r / v q$ & $19 / 91$ & $19 / 94$ & $|f /| \mid$ & $11 / 4 \pi$ & N/Ar & 4 \\
\hline Tr/TV & $19 / \wedge \mathrm{V}$ & $19 / 79$ & $|r / 9|$ & $11 / T F$ & N/VT & v \\
\hline$r Y / l \cdot$ & $19 / \cdot V$ & $10 / 9 F$ & $|r /| \cdot$ & $11 / \Delta \Delta$ & N/RT & $\wedge$ \\
\hline$r M / \cdot F$ & IV/G9 & $\mid \Delta / \Gamma \Delta$ & $11 / \wedge \Delta$ & $9 / 8 \wedge$ & $V / 99$ & १ (Internal) \\
\hline
\end{tabular}

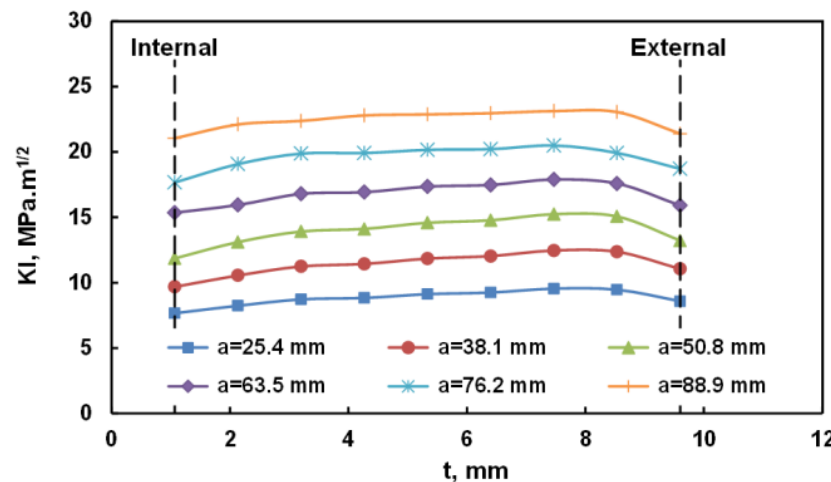

شكل ه - نمايش ضرايب شدت تنش روى جبهه ترك براى طول ترك هاى مختلف تحت فشار داخلى

يُ إس از بررسى رفتار عددى استوانه تركدار تحت فشـار داخلـى بـهـ

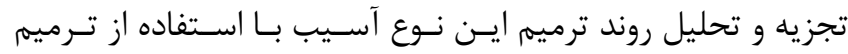

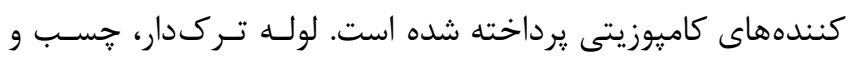

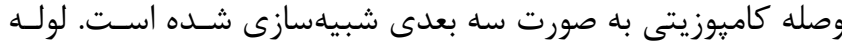

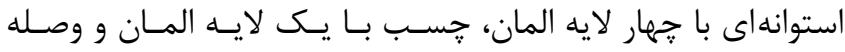

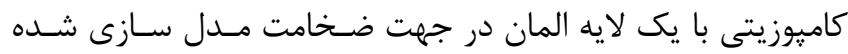

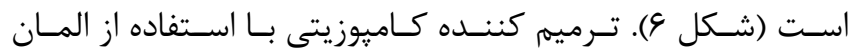

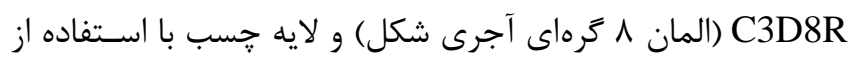

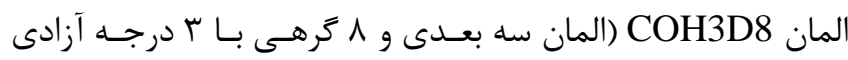

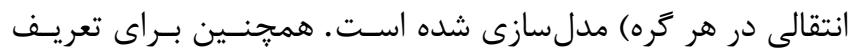

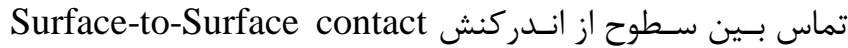
استفاده شده و اتصال سطوح به كمك قيد Tie برقـرار شـده اسـت. براى ترميمى و تقويت از كاميوزيتهاى بور /ايوكسى، كربن/ايوكسى،

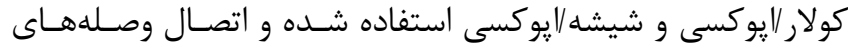

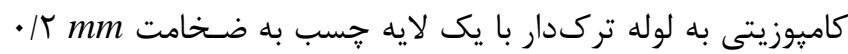

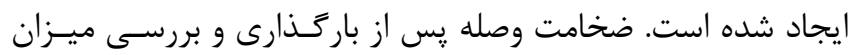

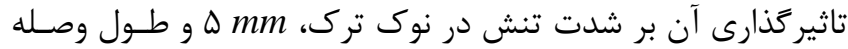




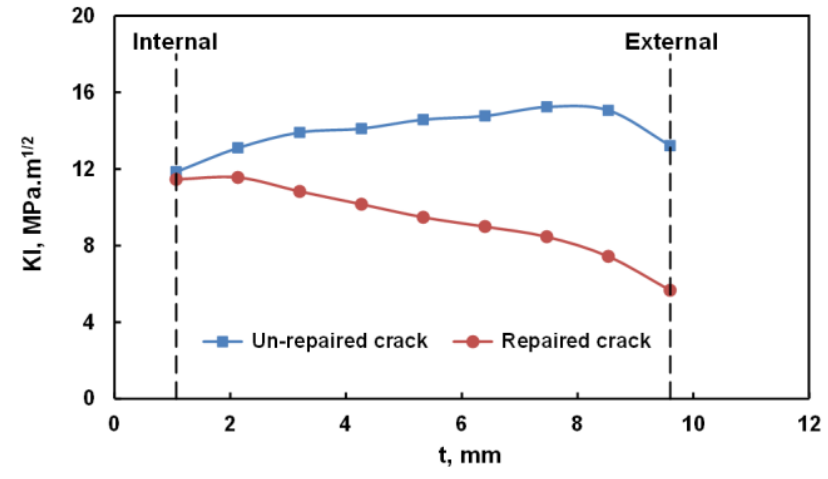

شكل 9 - ضرايب شدت تنش در طول ضخامت استوانه تركدار

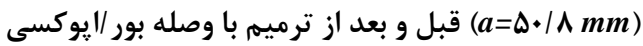

در ادامه به بررسى تـاثير يارامترهـاى جهـت گيـرى اليـاف، جــس

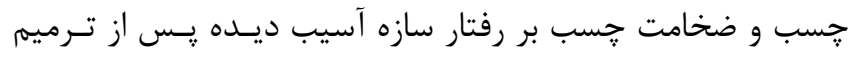

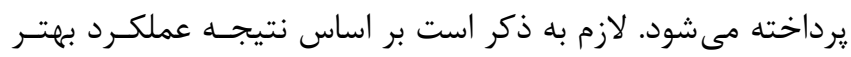

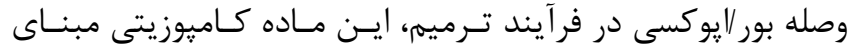
بررسى اثر يذيرى قرار گرفته است.

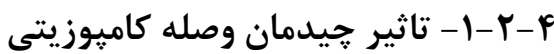

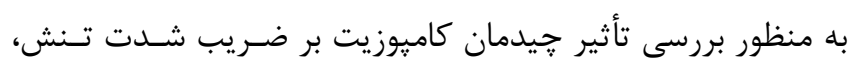

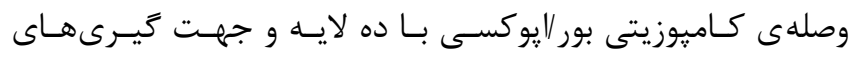

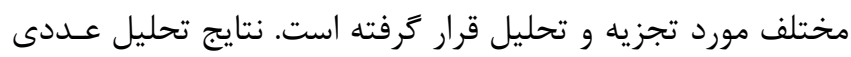

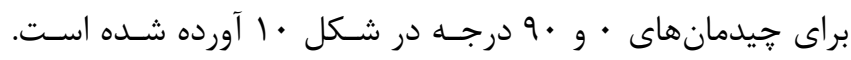

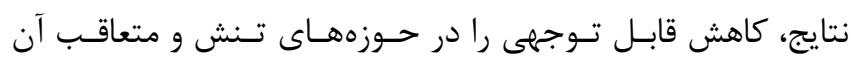
ضريب شدت تنش در نوك ترك به ازاى طــولهـاى مختلـف تـرك

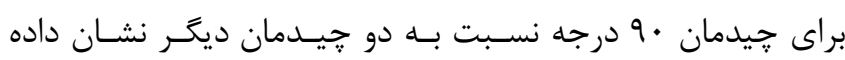

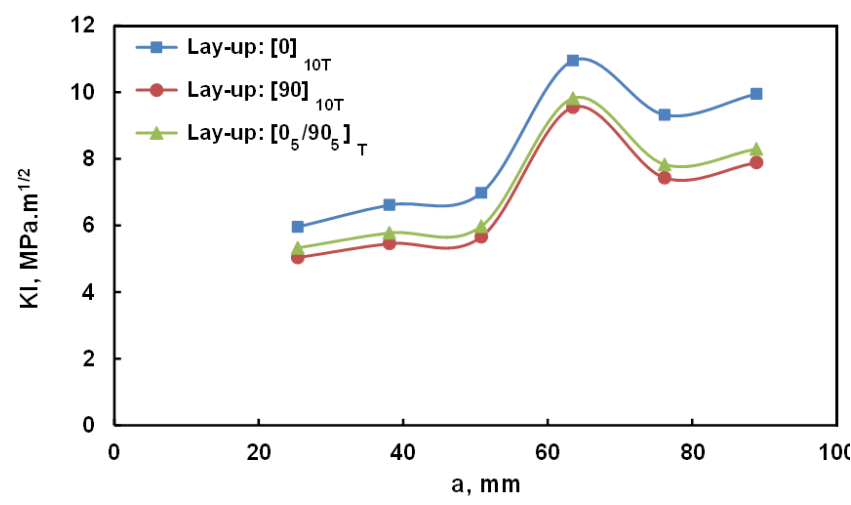

شكل •1 - اثر كاميوزيت بور /ايوكسى با هيدمان • و •9 درجه بر ضريب شدت تنش در استوانه ترميم شده

در ادامه به بررسى تاثير لايه گذارى هأ+ و هأt درجه بر افزايش قابليت باربرى استوانه تركدار يس از ترميم يرداخته شده است. نتايج حاصل در شكل II آورده شده است. همانطور كه ملاحظه
اثر افزايش ضخامت وصلههاى كاميوزيتى بر استحكام لوله تـركدار

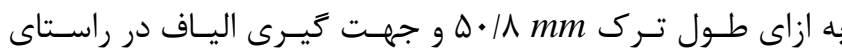
محيط استوانه در شكل ^مو جدول ل آورده شده است.

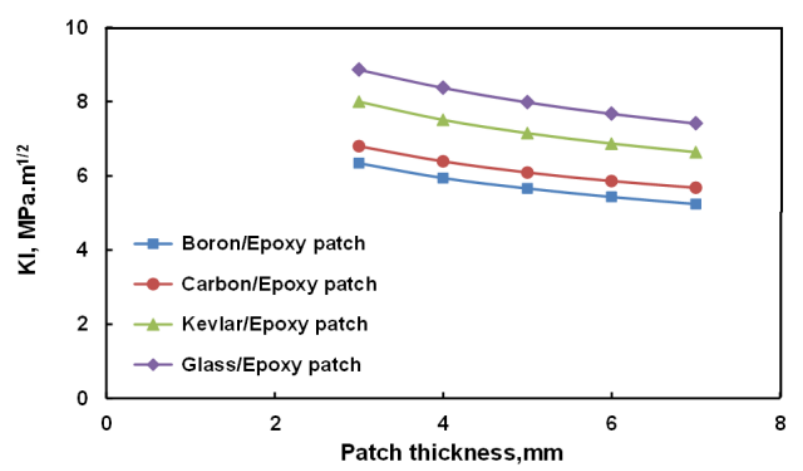

شكل 1 - اثر ضخامت وصلههاى كاميوزيتى بر ضرايب شدت تنش

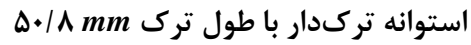

جدول V- نتايج تغيير ضخامت وصلههاى كاميوزيتى بر فر آيند ترميم

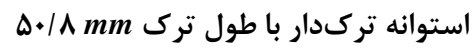

\begin{tabular}{|c|c|c|c|c|}
\hline \multicolumn{4}{|c|}{ 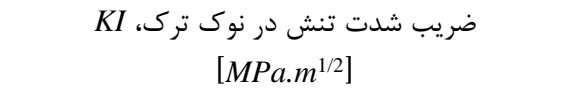 } & \multirow{2}{*}{ ضخامت وصله } \\
\hline 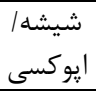 & | & | كربن/ & | بوركى & \\
\hline N/AG & $\Lambda / \cdot$ & s/ג. & $g / \mu F^{f}$ & $r$ \\
\hline N/rV & $V(\Delta)$ & $\varepsilon / \mu q$ & $\Delta / q F$ & f \\
\hline$V / 91$ & $V / 1 Q$ & 91.9 & $0 / 94$ & $\Delta$ \\
\hline$V / \& V$ & GIAV & $\Delta / \wedge \varphi$ & $\Delta / \mathcal{A}$ & 4 \\
\hline$V / 4 i$ & $\varepsilon|g| t$ & $\Delta / 9 \Lambda$ & $\Delta / T^{F}$ & V \\
\hline
\end{tabular}

همانطور كه مشاهده مىشود ماده كاميوزيتى بور/إوكسى به سـبب

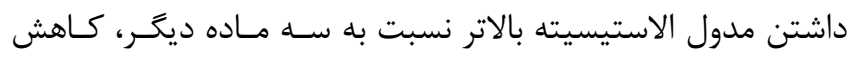
بيشترى را ضريب شدت تنش ايجاد مى كند. به بيان ديخر استحكام و مدول يانگ بالاى ماده ترميمى، سبب ميى شود تا ضـخامت وصـله

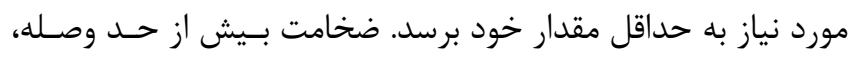

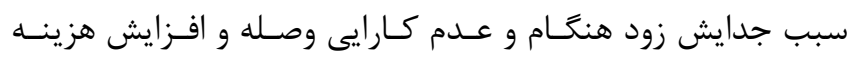

$$
\text { مىشود. }
$$

نتايج ضرايب شدت تنش نقاط مختلف جبهـهـه تـرك بــه ازاى طـول

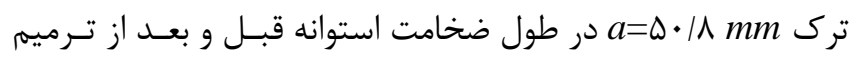
به كمك وصـله بور/ايوكسى در شـكل 9 آورده شـده اسـت. نتـايج ترميم در راس بيرونى ترك تاثير بيشترى را در كاهش شدت تــش

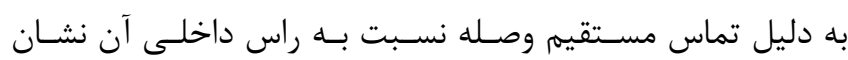
مى دهد. 


$$
\tau=\frac{E_{a}\left(U_{1}-U_{2}\right)}{2(1+v) e_{a}}
$$

كه درآن

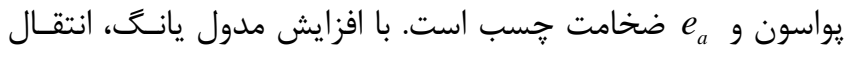
تنش بين لوله ترميم شـده و وصـله كـاميوزيتى افـزايش مسى يابـد.

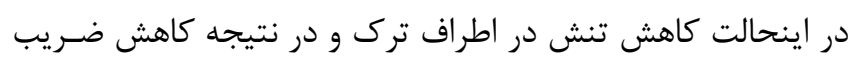
شدت تنش در اطراف نوك ترى را به همراه خواهد داشت.

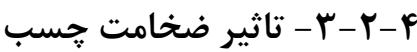

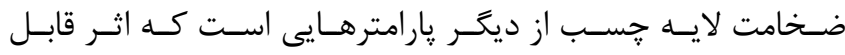

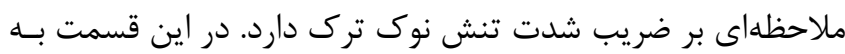

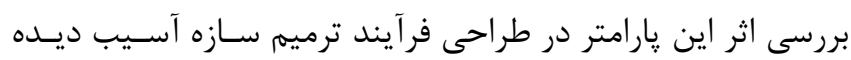

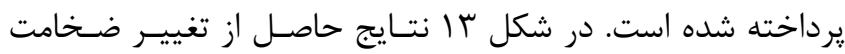

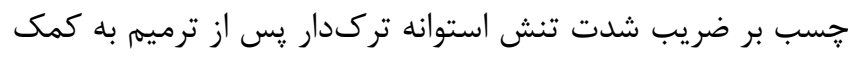

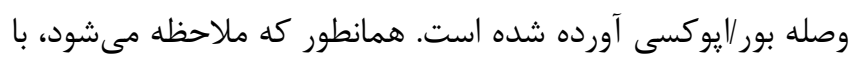

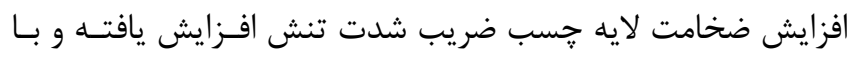

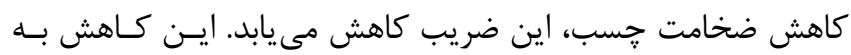

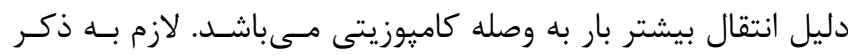

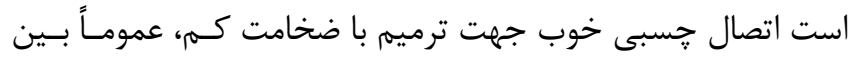

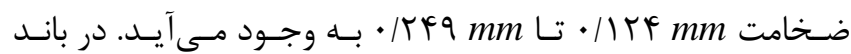
ضخيم جسب تمايل به ايجاد خلل و فرج وجود داشته و سبب ايجاد

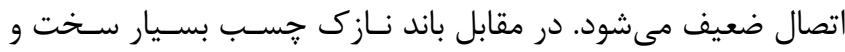

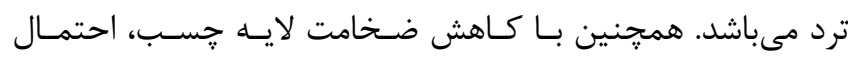

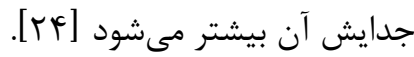

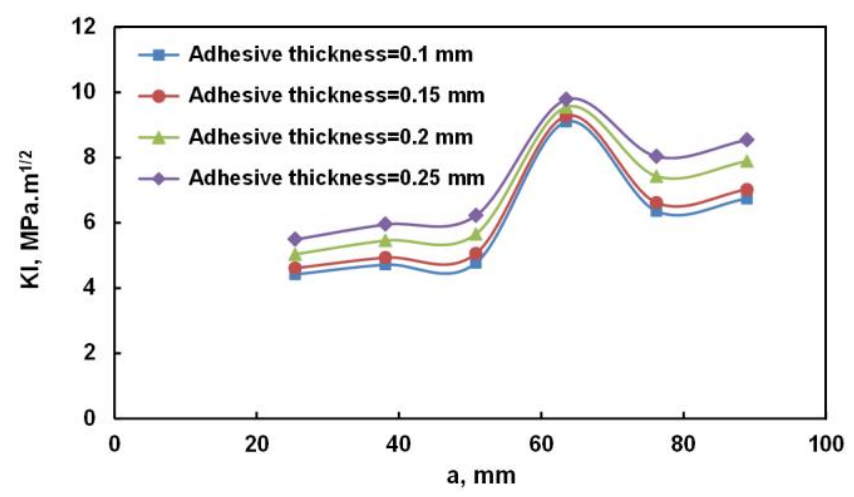

شكل سا - اثر ضخامت جسب بر ضريب شدت تنش مود اول به صورت

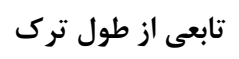

$$
\text { ه - نتيجه كيرى }
$$

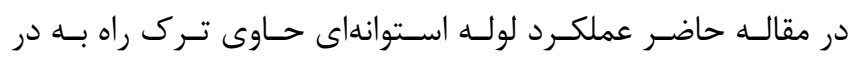
محيطى تحت فشـار داخلـى، قبـل و وهـس از تـرميمى بــا اسـتفاده از

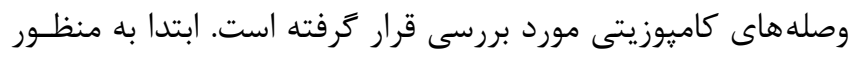

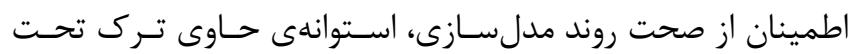

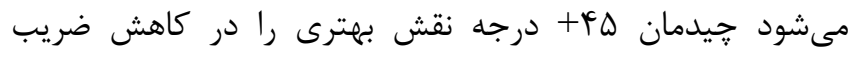

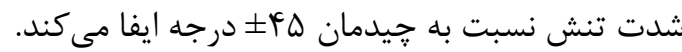

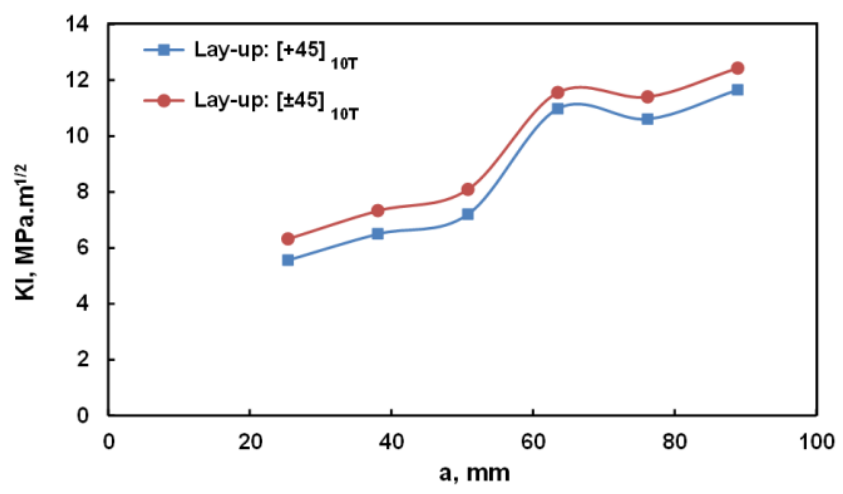

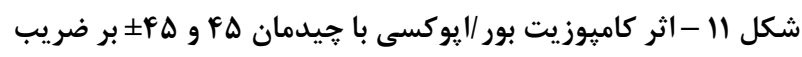
شدت تنش در استوانه ترميم شده

\section{- r-r-r}

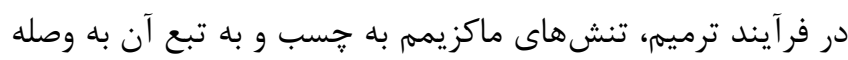

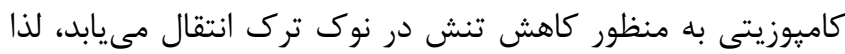
خواص جسب تاثير زيادى بر استحكام محل اتصال دارد. هر اندازه

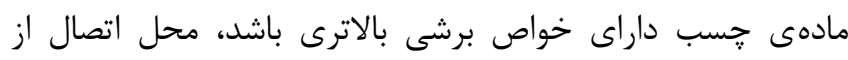

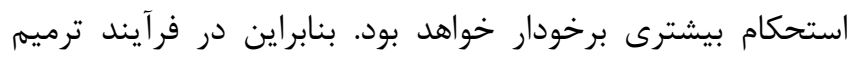

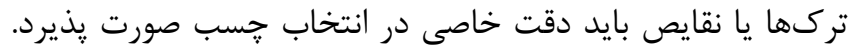

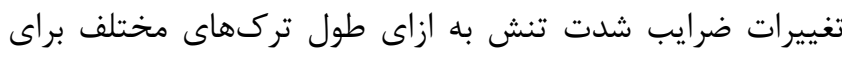

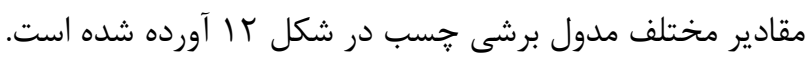

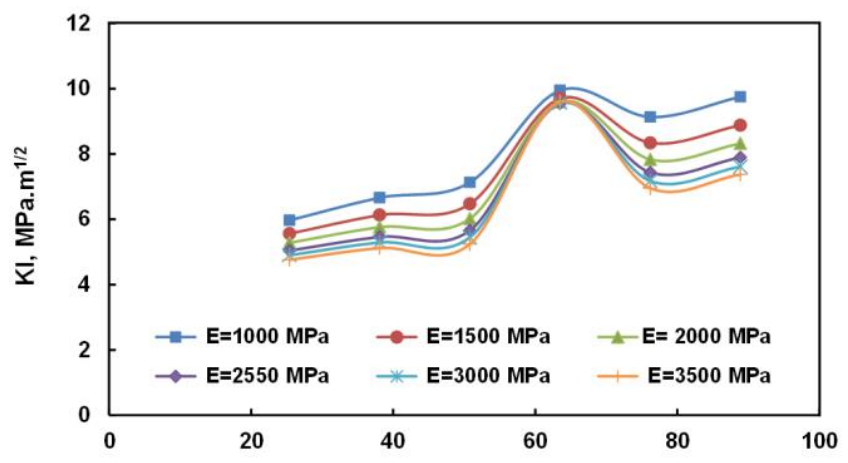

شكل זا - ضرايب شدت تنش در طول نوك ترك به ازاى مدول يانع مختلف جسب

نتايج نشان مىدهد با افزايش مدول يانگ جسب ميزان ضرايب

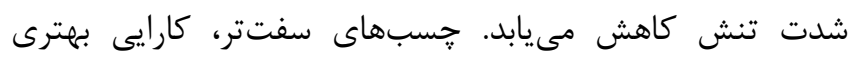
دارند. هرجند، افزايش مدول برشى جسب تاهي تاهش استحكام

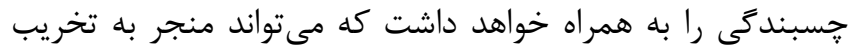

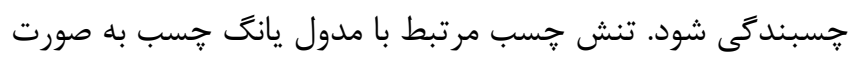

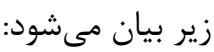




$$
\text { - } 9
$$

1- Lam, C.C., Cheng, J.J. and Yam, C.H., (2011), Finite element study of cracked steel circular tube repaired by FRP patching, Procedia Engineering, Vol. 14, p. 1106-1113.

2- Meriem-Benziane, M., Abdul-Wahab, S.A., Merah, N. and Babaziane, B., (2014), Numerical analysis of the performances of bonded composite repair with adhesive band in pipeline API X65, Advanced Materials Research, Vols. 875-877, p. 1101-1105.

3- Woo, K.S., Ahn, J.S. and Yang, S.H., (2016), Cylindrical discrete-layer model for analysis of circumferential cracked pipes with externally bonded composite materials, Composite Structures, Vol. 143, p. 317-323.

4- Zarrinzadeh, H., Kabir, M.Z. and Deylami, A., (2017), Crack growth and debonding analysis of an aluminum pipe repaired by composite patch under fatigue loading, Thin-Walled Structures, Vol. 112, p. 140-148.

5- Zarrinzadeh, H., Kabir, M.Z. and Deylami, A., (2017), Experimental and numerical fatigue crack growth of an aluminium pipe repaired by composite patch, Engineering Structures, Vol. 133, p. 24-32.

6- Benyahia, F., Albedah, A. and Bachir Bouiadjr, B., (2014), Stress intensity factor for repaired circumferential cracks in pipe with Bonded composite wrap, Journal of Pressure Vessel Technology, Vol. 136, p. 041201-1-5.

7- Ayatollahi, M.R., Azad, H. and Hashemi, R., (2007), Investigation of the behavior of cracked tubes reinforced with composite patch, $1^{\text {st }}$ Iranian Pipe and Pipeline Conference, Tehran. (In Persian)

8- Belhadri, D.E., Belhamiani, M., Bouzitouna, W.N. and Oudad W., (2019), Stress intensity factors analyses for external semi-elliptical crack for repaired gas-pipeline by composite overwrap under pressure, Frattura ed Integrità Strutturale, Vol. 49, p. 599-613.

9- Medjdoub, S.M., Bouadjra, B.B. and Abdelkader M. (2018), Optimization of the geometrical parameters of bonded composite wrap for repairing cracked pipelines, Frattura ed Integrità Strutturale, Vol. 46, p. 102-112

10- Valadi, Z., Bayesteh, H. and Mohammadi, S., (2018), XFEM fracture analysis of cracked pipeline with and without FRP composite repairs, Mechanics of Advanced Materials and Structures, In press.

11- Nabavi, S.M., Jamal-Omidi, M. and Sharifi H., (2018), Numerical Study of Effective Factors Caused by Composite Patch on Increasing the Performance of Semi-Elliptical Cracked Cylinder, Journal of Mechanical Engineering Tabriz University, Accepted paper. (In Persian)

12- Wang, L., Song, S., Deng, H. and Zhong, K. (2018), Finite-Element Analysis of Crack Arrest Properties of Fiber Reinforced Composites Application in Semi-Elliptical Cracked Pipelines, Applied Composite Materials, Vol. 25, p. 321-334.

$$
\begin{aligned}
& \text { نيروى كششى يكنواخت به صورت سه بعدى شبيهسازى شـده و بـاــا }
\end{aligned}
$$

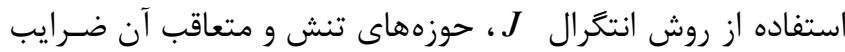

$$
\begin{aligned}
& \text { شدت تنش روى جبهه ترك به ازاى طول ترك هاى مختلف تعيسين }
\end{aligned}
$$

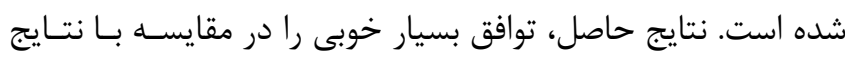

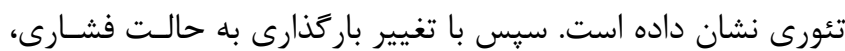

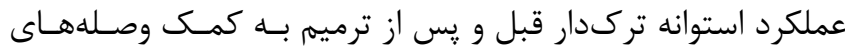

$$
\begin{aligned}
& \text { كاميوزيتى مورد بررسى قرار كرفته و نتايج ذيل حاصل شده است: } \\
& \text { • ضرايب شدت تنش قبل و پِّ از ترميم بر روى استوانهاى }
\end{aligned}
$$

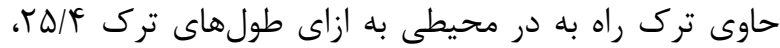

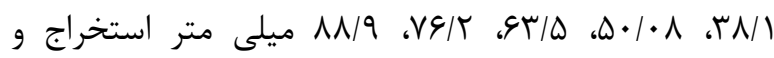

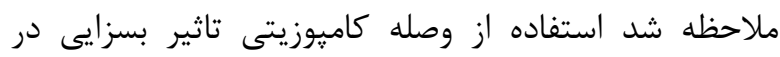

$$
\begin{aligned}
& \text { كاهش مقدار ضرايب تنش دارد. } \\
& \text { • ضرايب شدت تنش در ناحيه آسيب، با افزايش طول ترك دافي }
\end{aligned}
$$

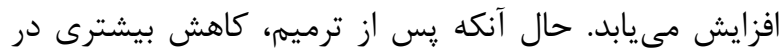

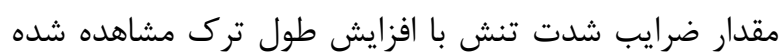

$$
\begin{aligned}
& \text { است. } \\
& \text { • مواد كاميوزيتى بور/ايوكسى و كربن/ايوكسى به سبب داشتن }
\end{aligned}
$$

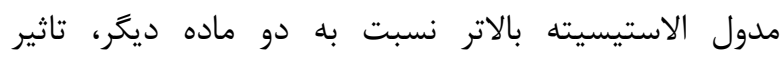

$$
\begin{aligned}
& \text { عمدهترى در فرآيند ترميم سازههاى آسيب ديده دارند. }
\end{aligned}
$$

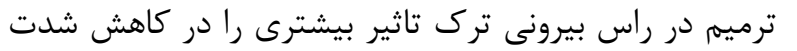

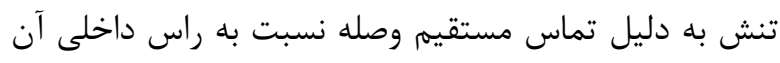

$$
\begin{aligned}
& \text { دارد. } \\
& \text { • افزايش ضخامت وصله و كاهش ضخامت جسب سبب افزايش }
\end{aligned}
$$

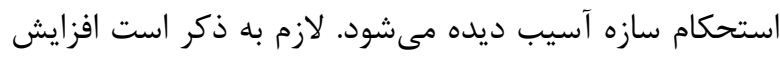

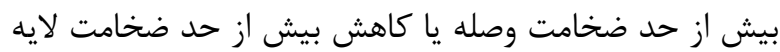

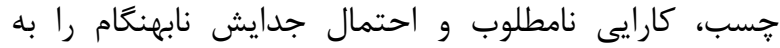

$$
\begin{aligned}
& \text { همراه خواهد داشت. }
\end{aligned}
$$

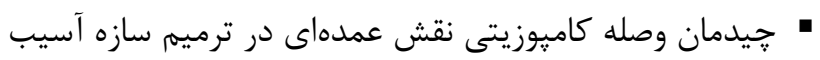

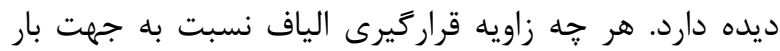

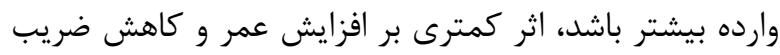

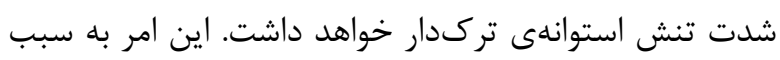

$$
\begin{aligned}
& \text { كاهش سفتى موثر وصله كاميوزيتى در جهت عمود بر راستاى } \\
& \text { ترك مى مباشد. } \\
& \text { • استحكام و مدول مناسب ماده ترميمى و خسب سبب }
\end{aligned}
$$

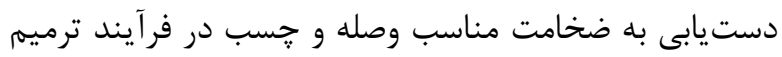

$$
\begin{aligned}
& \text { مىشود. }
\end{aligned}
$$

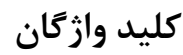




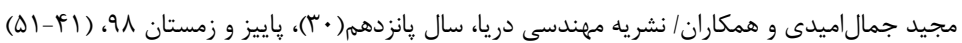

13- Esmaeel, R.A., Khan, M.A. and Taheri, F., (2012), Assessment of the environmental effects on the performance of FRP repaired steel pipes subjected to internal pressure, Journal of Pressure Vessel Technology, Vol. 134, p. 041702-1-7.

14- Shouman, A. and Taheri, F., (2011), Compressive strain limits of composite repaired pipelines under combined loading states, Composite Structures, Vol. 93, p. 1538-1548.

15- Ghaffari, M.A. and Hosseini-Toudeshky, H., (2013), Fatigue crack propagation analysis of repaired pipes with composite patch under cyclic pressure, Journal of Pressure Vessel Technology, Vol. 135, p. 031402-1-9.

16- Lyapin, A.A., Chebakov, M.I., Dumitrescu, A. and Zecheru, G., (2015), Finite-element modeling of a damaged pipeline repaired using the wrapped of a composite material, Mechanics of Composite Materials, Vol. 51, p. 333-340.

17- Lukács, J., Nagy, G., Török, I., Égert, J. and Pere, B., (2010), Experimental and numerical investigations of external reinforced damaged pipelines, Procedia Engineering, Vol. 2, pp. 1191-1200.

18- Malekan, M. and Cimini Jr, C.A., (2018), Finite element analysis of a repaired thin-walled aluminum tube containing a longitudinal crack with composite patches under internal dynamic loading, Composite Structures, Vol. 184, p. 980-1004.

19- Meriem-Benziane, M., Abdul-Wahab, S.A., Zahloul, H., Babaziane, B., Hadj-Meliani, M. and Pluvinage, G., (2015), Finite element analysis of the integrity of an API X65 pipeline with a longitudinal crack repaired with single- and double-bonded composites, Composites Part B, Vol. 77, p. 431-439.

20- Doostvandi, B. and Zeinedini, A., (2019), Repair of inclined notches in the pressurized steel pipes using laminated composites, Material Design \& Processing Communications, In press.

21- Nabavi, S.M., Pourabdol, A. and Jamal-Omidi, M., (2018), Numerical study of the effect of the composite patches on the stress intensity factors for a circumferential fully crack in pipes, Journal of Structural and Construction Engineering (JSCE), Accepted paper. (In Persian)

22- Jamal-Omidi, M., Falah, M. and Taherifar, D., (2014), 3-D fracture analysis of cracked aluminum plates repaired with single and double composite patches using XFEM, Vol. 50, p.525-539.

23- Takahashi, Y., (2002), Evaluation of leak-beforebreak assessment methodology for pipes with a circumferential through-wall crack. Part I: stress intensity factor and limit load solutions, International Journal of Pressure Vessels and Piping, Vol. 79, p. 385-392.

24. Okafor A.C., Singh N., Enemuoh U.E. and Rao, S.V., (2005), Design, analysis and performance of adhesively bonded composite patch repair of cracked aluminum aircraft panels, Composite Structures, Vol. 71, p. 258-270. 